\title{
4. 1990: LOS PRIMEROS PASOS HACIA LA DEMOCRACIA EN LA ANTIGUA UNIÓN SOVIÉTICA Y EN LA EUROPA DEL ESTE
}

\author{
CARLOS FLORES JUBERÍAS \\ Departamento de Derecho Constitucional \\ Universidad de Valencia
}




\section{SUMARIO}

I. Introducción.-II. Alemania Oriental: Sentar las bases para la reuNIFICACIÓN.-III. Bulgaria: Ralentizar el CaMBIO.-IV. Las repúblicas CHECA Y ESLOVACA: RESTAURAR LA DEMOCRACIA Y REPLANTEAR EL FEDERALISMO.-V. HUNGRÍA: UNA TRANSICIÓN ORDENADA.-VI. POLONIA: LA PAULATINA DEMOCRATIZACIÓN.-VII. RUMANIA: ¿UNA REVOLUCIÓN TRAICIONADA?VIII. La aNTIGUA UNIÓN SOVIÉTICA: EL CAMINO HACIA LA DEMOCRACIA Y HACIA LA DISGREGACIÓN. - IX. LA ANTIGUA YUGOSLAVIA: LOS PRECURSORES DE LA DEMOCRATIZACIÓN Y LOS ÚLTIMOS REDUCTOS DEL LENINISMO. 


\title{
4. 1990: LOS PRIMEROS PASOS HACIA LA DEMOCRACIA EN LA ANTIGUA UNIÓN SOVIÉTICA Y EN LA EUROPA DEL ESTE (*)
}

POR

\author{
CARLOS FLORES JUBERÍAS \\ Departamento de Derecho Constitucional \\ Universidad de Valencia
}

"Debería llorar de alegría porque todo esto haya sucedido tan rápida y tan sencillamente. Y debería llorar de rabia porque todo esto haya tardado tantísimo en suceder.»

(Wolf Biermann)

\section{INTRODUCCIÓN}

Los procesos electorales que a lo largo del año crucial de 1990 se desarrollaron en la antigua Unión Soviética y en los países europeos sometidos a su esfera de influencia supusieron sin duda hitos definitivos en los procesos de transición hacia la democracia vividos por cada uno de esos países. Si una de las características más fundamentales del totalitarismo es la omnipresencia de un partido único, apenas deslindado de las instituciones del Estado y si, por contra, una de las características de la democracia es el pluralismo político, no resultará exagerado afirmar que, en la medida que son las elecciones libres las que permiten transformar un sistema de

(*) El presente estudio fue redactado en la Universidad de Valencia en julio de 1991, y rehecho más tarde, en junio de 1993, en la Universidad de CaliforniaSan Diego. El autor está en deuda de gratitud con el Departamento de Ciencia Política de la UCSD -y, en particular, con los Profs. Paul Drake y Ellen T. Comisso- por su inmejorable acogida, así como con el Ministerio español de Educación y Ciencia y el Council for International Exchange of Scholars por el imprescindible apoyo económico proporcionado al amparo del Programa MEC/Fulbright. 
partido único en un sistema multipartidista, son éstas quienes marcaron el auténtico punto de inflexión en el paso del totalitarismo a la democracia.

Más aún: en este caso podría también afirmarse que dichos probesos electorales - y en particular los que condujeron a la libre elección, por vez primera, de sus órganos legislativos- supusieron un auténtico "punto de no retorno" en sus respectivos procesos de transición. Pendientes como en pocas ocasiones de la amenaza de la involución, el simple hecho de haber sido capaces de celebrar unos comicios de forma ordenada y de haber consolidado así un gobierno dotado de un sólido apoyo popular, acabaría constituyendo una auténtica garantía frente a la tentación de un retorno por la fuerza a la ortodoxia del marxismo-leninismo. Y ello más todavía si hemos de tener en cuenta el escaso éxito que en la mayor parte de los casos cosecharian los herederos ideológicos - reformados incluso- del régimen caído.

En última instancia, las mencionadas elecciones parlamentarias sirvieron para asentar sobre bases firmes los imprescindibles procesos de reforma económica, política y social que cuatro decenios de inmovilismo habian hecho inaplazables pero que no era posible plantear sin antes haber hecho un sondeo en profundidad entre todos los sectores sociales implicados. En suma, podríamos afirmar que tales procesos electorales supondrian respecto de las reformas en curso a la vez un argumento de legitimidad, un factor de relanzamiento y una salvaguardia ante la tentación reaccionaria.

Todo ello obliga a concluir que, pese a la intensidad de los cambios acontecidos desde entonces hasta ahora, sólo tras un análisis detallado de las contiendas electorales desarrolladas en la URSS y la Europa del Este durante su proceso de transición a la democracia es posible entender el sentido del cambio experimentado en estos países, su ritmo, su dirección y sus carencias. A proporcionar unos instrumentos elementales para el conocimiento de todos los procesos que se desarrollaron durante el pasado año de 1990 se encaminan estas líneas.

\section{ALEMANIA ORIENTAL: SENTAR LAS BASES PARA LA REUNIFICACIÓN}

La transición hacia la democracia en la ya desaparecida República Democrática Alemana presentaría respecto del resto de los procesos de su entorno una particularidad fuertemente condicionadora. Se trata, naturalmente, de la constante presencia del problema jurídico, político y económico de la reunificación alemana. La desaparición de la Unión Soviética como potencia militarmente hegemónica en la Europa Central y del Este supondría la reaparición en la mayor parte de estos países de na- 
cionalismos casi olvidados y generaría en alguno de ellos reivindicaciones fronterizas encaminadas a la reunificación de partes de una misma etnia o a la separación de naciones diferentes hasta entonces forzadas a convivir juntas. Sin embargo, en ningún caso una reivindicación de corte nacionalista poseería tanta fuerza y recabaría tanto protagonismo como en el caso alemán. Es por ello que, entiendo, puede afirmarse sin exageración que las elecciones parlamentarias alemanas de marzo de 1990 serían planteadas más que como la ocasión de diseñar el futuro modelo de estado germanooriental, como la oportunidad de elegir de qué modo y a qué ritmo se deseaba la reunificación con la otra Alemania. Siendo la mayor parte de los alemanes del este inequívocamente favorables a la más rápida de las vías posibles, el triunfo electoral fue en buena lógica para quien de modo más rotundo se manifestó en ese sentido y para quien con más claridad demostró su capacidad para llevar a buen puerto un proceso de semejante complejidad.

El desmoronamiento del régimen marxista de la Alemania Oriental comenzaría a gestarse durante el verano de 1989 . Su raíz debería buscarse, fundamentalmente, en el creciente descontento que había provocado el masivo fraude electoral perpetrado en las elecciones locales del inmediato mes de mayo, así como en el ejemplo renovador que por esas mismas fechas brindaban ya polacos, soviéticos y húngaros. La eclosión de tales protestas se verificaría durante los históricos meses de octubre y noviembre, forzando las dimisiones de Erich Honecker, del Gobierno de Willi Stoph y de todo el Politburó del SED, así como la deseada apertura de las fronteras. De este modo, podría afirmarse que a mediados de noviembre el régimen comunista estaba prácticamente liquidado, y sólo le restaba operar una transición hacia la democracia lo más limpia y rápida posible. Así, el 17 de noviembre, el nuevo Primer Ministro Hans Modrow - comunista reformador- anunciaría formalmente la convocatoria de elecciones parlamentarias para la primavera siguiente, verificándose pocos dias más tarde la abolición de las disposiciones constitucionales sancionadoras del rol dirigente del SED, la sustitución en la Jefatura del Estado del delfín de Honecker, Egon Krenz, por el líder liberal Manfred Gerlach, y la apertura de negociaciones entre el nuevo gobierno y la oposición.

La aparición de grupos opositores organizados sería en Alemania más rápida si cabe que en los demás países del entorno. A ello contribuiría un buen número de motivos, que irían desde la mayor tradición democrática de los alemanes hasta el siempre presente ejemplo de la Alemania Occidental, sin olvidar tampoco el hecho de que durante todo el régimen comunista hubiesen sobrevivido en la RDA cuatro partidos -cristianodemócratas, liberales, campesinos y nacionaldemócratasque, llegado el momento, olvidarían su largo historial de colaboracionis- 
mo con el régimen para colocarse inequívocamente del lado de la oposición, sirviendo así de puente entre unos y otros.

Con todo, los primeros grupos organizados serían de impronta netamente germanooriental y de talante más bien socialista y democrático. Tal sería el caso de Nuevo Foro (NF), de Democracia Ahora (DJ), de Izquierda Unida (VL) y, sobre todo, del Partido Socialdemócrata (SDP). Liderado por el historiador Ibrahim Boehme, el SDP abogaría en su programa por el pluralismo político, la democracia parlamentaria, la economía de mercado, la libertad sindical, el derecho de huelga, el pacifismo y el autogobierno local y regional. Celoso inicialmente de su independencia respecto de la poderosa socialdemocracia germanooccidental, no tardaría sin embargo demasiado en beneficiarse de su apoyo, para acabar modificando sus siglas e integrándose plenamente en una única fuerza. En tales circunstancias no parecía descabellado pensar en el SPD como el gran vencedor de las elecciones previstas para marzo.

Igualmente autóctono, pero de talante más bien conservador, sería el grupo Amanecer Democrático, liderado por el abogado Wolfgang Schnur. Éste haría especial hincapié desde el momento de su aparición en la revisión constitucional, la división de poderes, la libertad de asociación y la drástica reducción del aparato de seguridad del Estado.

Los partidos satélite del comunista no tardarían tampoco en replantear su futuro en el nuevo régimen que se avecinaba. Dotados de cierta estructura organizativa, sólidas bases humanas y económicas y una inestimable presencia en la Administración Pública, su principal tarea era la de desmarcarse del pasado, haciendo creíble su apuesta por la democracia. El Partido Liberal Democrático (LDPD) de Manfred Gerlach sería quien más ventaja llevase en ello, toda vez que había venido siendo desde hacia años el más díscolo de los socios del SED y habia recibido desde el primer momento el interesante apoyo de los liberales de la RFA. El Partido Campesino Alemán (DBD) extraería sus principales apoyos de las zonas rurales, reivindicando en su programa político la necesidad de compatibilizar en la futura Alemania la economía de mercado con las ventajas de la agricultura colectivizada. El positivo papel de su líder, Günther Maleuda, como Presidente de la Volkskammer desde noviembre de 1989, sería para la DBD el mejor aval. Por su parte, el Partido Nacional Demócrata Alemán (NPDP) trataría de presentarse a sí mismo como el partido centrista por excelencia, pero su escaso predicamento, así como su falta de liderazgo, darían bien pronto al traste con sus aspiraciones.

Pero sin ninguna duda sería la Unión Cristianodemócrata (CDU) la que mejor sabría adaptarse a las nuevas inquietudes de los alemanes del 
Este. De entrada, sería la primera fuerza en renovar sus cuadros, sustituyendo al desacreditado Gerhard Goetting por el conocido abogado Lothar de Maizière. Pero además, sería la que primero y con más insistencia apoyaría una rápida reunificación y una radical transformación del sistema económico germanooriental. El apoyo de la CDU germanooccidental le tardaría en llegar, fundamentalmente a causa de su largo historial como satélite del SED, pero una vez conseguido se convertiría en el elemento clave de su triunfo.

Por su parte, los partidos de la República Federal también tomarían en muchos casos la iniciativa en la tarea de tender puentes hacia la otra Alemania. Así, la CSU bávara propiciaría la aparición, ya en enero de 1990, de su "gemela" germanooriental, la DSU (Unión Social Alemana), al tiempo que los liberales del FDP apoyarían pocas semanas más tarde la creación en la RDA de un partido con siglas idénticas a las suyas. En ambos casos lo que habia era un trasfondo de desconfianza en las fuerzas cristianodemócratas y liberales ya existentes -respectivamente la CDU y el LDPD—, cuya sinceridad democrática y, sobre todo, cuya capacidad de gestión estaban aún por demostrar.

En última instancia, el SED afrontaría la carrera electoral profundamente transformado. La crisis política que había llevado a las sucesivas dimisiones de Honecker y de Krenz había dejado al partido profundamente marcado. Además, las continuas revelaciones que durante esos días aflorarian sin cesar en torno a los privilegios económicos de las altas jerarquías del Estado, a los abusos continuos de la Policía Secreta y al caótico estado de las finanzas públicas sumirían al partido y a toda su cúpula en el más absoluto de los descréditos y reduciría el número de sus miembros de 2,3 millones a poco más de 700.000. Se imponía, pues, una profunda transformación de las estructuras y un radical cambio en la ideología y en la imagen. Ambas cosas se verificarían en la Conferencia Extraordinaria que el SED inauguraría el 8 de diciembre.

La necesaria trasformación estructural se verificaría mediante la sustitución del viejo Politburó del Partido por un Comité Ejecutivo de nuevo cuño. El cambio de imagen, por su parte, se concretaría en la elección de Gregor Gysi como presidente del partido y en la adopción de una nueva denominación: la de Unidad Socialista de Alemania/Partido del Socialismo Democrático (SED/PDS), que pronto se quedaría, simplemente, en PDS. Gysi, abogado, de 42 años, judío de origen y antiguo Ministro de Cultura y de Cultos, parecía tener poco que ver con la anterior cúpula del partido y, con la colaboración del Primer Ministro Hans Modrow, no tardaría en imprimirle a éste una impronta marcadamente progresista y occidentalizada, presentándole como el abanderado de la solidaridad social 
y el defensor de los débiles y los desprotegidos, primeras víctimas sin duda del inminente retorno al capitalismo.

El sistema electoral aplicable vendría contenido en la Ley Electoral de 20 de marzo de 1990, que hallaría su complemento en las leyes sobre partidos políticos y coaliciones electorales de 21 de febrero. En síntesis, la Ley proponía un sistema proporcional con cálculo de escaños a nivel nacional y posterior distribución entre las listas territoriales de cada partido. Las circunscripciones resultarian ser los quince Bezirke preexistentes, más Berlín Este, y aunque se contemplaba la exigencia de un mínimo de votos para poder acceder al reparto de escaños, éste era tan insignificante - el $0,25 \%$ del total nacional- que apenas si generaría efecto alguno. Se trataba, pues, de un sistema extremadamente proporcional destinado en un principio a permitir la entrada en la Volkskammer de prácticamente todas las fuerzas políticas existentes, por más que las cláusulas prohibitivas de la formación de grupos de corte militarista o fascista fuesen utilizadas para impedir la presencia en Alemania Oriental de fuerza política alguna que pudiera asemejarse a los Republikaner germanoocidentales.

Aun así, las semanas previas a la presentación de las candidaturas contemplarían una febril formación de alianzas electorales, lógicas si hemos de tener en cuenta las escasas diferencias programáticas que mediaban entre un buen número de fuerzas políticas y la escasa base humana, económica y organizativa de la mayor parte de ellas. Así, el $\mathbf{5}$ de febrero se constituiría en Berlín, y bajo los auspicios del Canciller Kohl, la Alianza por Alemania (AfD), en la que se integrarían la CDU, la DSU y Amanecer Democrático. Una semana después, el Ministro Federal de Exteriores, Hans Dietrich Genscher - germanooriental de nacimiento-, lograría su propósito de fundir en uno sólo los distintos partidos liberales de la RDA. Nacería así la Liga de Demócratas Libres (BFD), en la que se integrarian el LDPD, el FDP y el Partido del Foro Democrático (DFP), escindido de Nuevo Foro. Éste último, marginado progresivamente por el rumbo de los acontecimientos, acabaría integrándose también en una coalición electoral, la Alianza 90 (Bündnis 90), en la que participarían también Democracia Ahora y el grupo Iniciativa por la Paz y los Derechos Humanos. La lista de las alianzas se completaría, finalmente, con la que formarían los Verdes y la Liga Independiente de Mujeres (UFV), que concurrirían a las urnas como Grüne/Frauen.

La campaña electoral se desarrollaría con gran animación y exquisita limpieza. A lo primero contribuiría la misma efervescencia política del momento, a la que no sería extraña una particular acentuación del sentimiento nacionalista alemán que sembraría la preocupación en más de una cancillería occidental. La misma participación en la campaña de se- 
ñalados líderes políticos de la RFA como Willi Brandt, Hans D. Genscher y el propio Canciller Kohl despertaría un interés entre los electores mayor incluso que el generado por los propios candidatos, normalmente poco conocidos y menos habituados a ese tipo de actos. La limpieza de la campaña vendría asegurada por la existencia de una Comisión Electoral $\mathrm{Na}$ cional de extracción multipartidista, que se encargaría de verificar el escrutinio y proclamar los resultados finales, y por una Comisión de Medios, que supervisaría el equitativo reparto de los espacios radiotelevisivos públicos. Además, no hay que olvidar que, prácticamente desde el primer momento, los órganos de poder del antiguo régimen se verían suplantados en su labor decisoria por la "Zentraler Runden Tisch", la mesa redonda en donde se gestarían las principales decisiones en el proceso democratizador mediante el acuerdo entre el gobierno comunista y la oposición democrática. $Y$ tampoco hay que olvidar que desde el 5 de febrero de 1990 el Gobierno reformista de Modrow, que ya había brindado varias carteras a liberales, democristianos, campesinos y nacionaldemócratas, se vería obligado a abrirse aún más, convirtiéndose así en un auténtico gobierno de concentración nacional.

La polémica en torno a la reunificación no tardaría en convertirse en el objeto central de la campaña. De hecho, nadie parecía ver en los candidatos de los diferentes partidos los futuros gobernantes de una Alemania Oriental -esta vez sí- plenamente democrática, sino más bien los gestores de una integración que cada día que pasaba parecía más inminente, más deseada, más factible y más necesaria. Las posturas de los distintos partidos diferirian al respecto. Para el PDS la reunificación sería, sencillamente, un error. En la RDA, argumentaban, se habían cometido numerosos errores, pero el balance general no dejaba por ello de ser positivo y la pretendida reunificación no haría sino acabar con los logros sociales conquistados por los trabajadores con tanto esfuerzo. El mensaje, obviamente falso, resultaba sin embargo de interés para las grandes masas de funcionarios del Estado y de profesionales escasamante preparados o al servicio de empresas altamente deficitarias, que veían con razón amenazados sus empleos ante la irrupción del capitalismo y la competitividad. Por su parte, los grupos de oposición más radicales, como Alianza 90, Izquierda Unida y los Verdes enfatizarían la necesidad de no caer en manos del capitalismo salvaje como si éste fuese la única solución para la RDA, postulando la demolición del aparato comunista pero no la de todos sus logros sociales.

Sin embargo, la mayor parte de la fuerzas políticas contendientes -y desde luego, las apoyadas por los tres grandes partidos germanooccidentales - acabarían apostando claramente por la reunificación. Las diferencias se plantearían aquí respecto del cómo. La Alianza y los liberales defenderían la vía del artículo 23 de la Grundgesetz federal, esto es, el 


\section{Cuadro I}

\section{REPÚBLICA DEMOCRÁTICA ALEMANA}

Elecciones parlamentarias

18 de marzo de 1990

Participación: 11.604 .418 electores $(93,38 \%)$

Cámara del Pueblo (Volkskammer): 400 escaños

\begin{tabular}{|c|c|c|c|c|c|c|c|c|c|}
\hline . & $\begin{array}{l}\text { Votos } \\
(n .9)\end{array}$ & $\begin{array}{l}\text { Votos } \\
(\%)\end{array}$ & $\begin{array}{l}\text { Berlin } \\
\text { (\%) }\end{array}$ & $\begin{array}{l}\text { Mecklen. } \\
\quad(\%)\end{array}$ & $\begin{array}{l}\text { Brandem. } \\
\quad(\%)\end{array}$ & $\begin{array}{l}\text { A Sajonia } \\
(\%)\end{array}$ & $\begin{array}{c}\text { Turingia } \\
(\%)\end{array}$ & $\begin{array}{l}\text { Sajonia } \\
\text { (\%) }\end{array}$ & $\begin{array}{c}\text { Escaños } \\
\left(n . .^{\prime}\right)\end{array}$ \\
\hline Alianza para Alemania (CDU/DSU/DA) ............... & 5.544 .474 & 48,04 & 21,5 & 39,3 & 38,5 & 47,8 & 60,2 & 57,5 & 192 \\
\hline CDU (Unión Cristiano Demócrata) ................ & 4.710 .598 & 40,82 & 18,3 & 36,4 & 34,0 & 44,7 & 53,0 & 43,6 & 163 \\
\hline 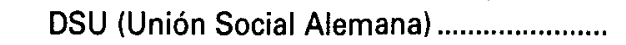 & 727.730 & 6,31 & 2,2 & 2,3 & 3,7 & 2,4 & 5,6 & 13,2 & 25 \\
\hline DA (Amanecer Democrático) .............................. & 106.146 & 0,92 & 1,0 & 0,6 & 0,8 & 0,6 & 1,6 & 0,9 & 4 \\
\hline SPD (Partido Socialdemócrata Alemán)............. & 2.525 .534 & 21,88 & 34,9 & 23,9 & 28,9 & 23,6 & 17,4 & 15,1 & 88 \\
\hline $\begin{array}{l}\text { PDS (Partido del Socialismo Democrático) ....... } \\
\text { BFD (Liga de los Demócratas Libres: }\end{array}$ & 1.892 .381 & 16,40 & 30,2 & 22,4 & 18,4 & 14,0 & 11,2 & 13,3 & 66 \\
\hline $\begin{array}{l}\text { LDP/FDP/DFP) ..................................... } \\
\text { Bündnis'90 (Alianza'90: Nuevo Foro/ }\end{array}$ & 608.935 & 5,28 & 3,0 & 3,6 & 4,8 & 7,7 & 4,6 & 5,7 & 21 \\
\hline Democracia Ahora) ................................ & 336.074 & 2,91 & 6,3 & 2,3 & 3,3 & 2,2 & 2,0 & 3,0 & 12 \\
\hline $\begin{array}{l}\text { DBD (Partido Campesino Democrático) ............. } \\
\text { Grüne/Frauen (Los Verdes/Mujeres }\end{array}$ & 251.226 & 2,18 & - & - & - & - & - & - & 9 \\
\hline 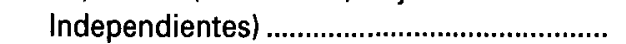 & 226.932 & 1,97 & 2,7 & 2,0 & 2,1 & 1,8 & 2,1 & 1,7 & 8 \\
\hline NDP (Partido Nacional Demócrata)......................... & 44.292 & 0,38 & - & - & - & - & - & - & 2 \\
\hline DFV (Liga de Mujeres Demócratas) ...................... & 38.033 & 0,33 & - & - & - & - & - & - & 1 \\
\hline VL (Izquierda Unida).............................................. & 20.342 & 0,18 & - & - & - & - & - & - & 1 \\
\hline
\end{tabular}


restablecimiento de los länder germanoorientalesy la entrada de cada uno de ellos, a petición propia, en la RFA. En cambio, el SPD se mostraría más partidario de enfocar la cuestión como un pacto entre Estados: una Volkskammer democráticamente elegida acordaría con el Bundestag germanooccidental la formación de una comisión constitucional conjunta, que elaboraría un texto que más tarde sería ratificado por ambas Cámaras. En suma, los democristianos abogaban por una integración de los territorios de la RDA en la RFA; una vía rápida y efectiva, que no precisaba de reformas institucionales de demasiada envergadura y que se sustentaba en un argumento histórico de enorme sencillez: la RFA era el Estado de todos los alemanes, los occidentales fueron libres para incorporarse a ella en 1949; los orientales, que se hallaban entonces bajo la dominación de una potencia extranjera, no lo han sido hasta ahora que cesó tal dominación. Lo que el SPD proponía, en cambio, era una vía más lenta y trabajosa, que intentaba correr un velo sobre el pasado de las dos Alemanias y empezar a consolidar, casi desde cero, un nuevo orden institucional.

La respuesta de los alemanes no dejaría lugar a dudas. La Alianza por Alemania arrollaría al resto de los contendientes (véase cuadro I), colocándose, con un $48 \%$ de los votos y 192 escaños, en el mismo borde de la mayoría absoluta. EI SPD quedaría, para sorpresa de la mayor parte de los observadores, muy por debajo de lo que le habían pronosticado los sondeos -menos del $22 \%$ de los votos y 88 escaños-, mientras que el PDS, también sorprendentemente, recogería un estimable $16 \%$ de los votos que le proporcionaría 66 escaños. Los grandes derrotados de la jornada serían, sin embargo, los grupos opositores radicales -principalmente Alianza 90-, que tras haber sido los precursores de la oposición al régimen de partido único se encontraban ahora ante porcentajes de voto realmente ínfimos, incluso en ciudades que como Leipzig o Dresden, habian sido el marco primero de sus movilizaciones.

El reparto territorial de los votos sería particularmente curioso. En términos generales, podría decirse que el escrutinio revelaría la existencia en el territorio germanooriental de dos áreas bien diferenciadas. De una parte, la conformada por los Bezirke del sur y el oeste - lo que poco después serian los Länder de Sajonia, Sajonia/Anhalt y Turingia-, de mayoría claramente conservadora, y por otra la conformada por los territorios del nordeste -Mecklemburgo, Brandemburgo y Berlín-, de orientación más bien izquierdista. Así, mientras que la CDU llegaría a conseguir en los distritos de Sajonia y Turingia porcentajes siempre superiores al $50 \%$ - llegando casi al $60 \%$ en Dresden, y superándolo en Erfurt y Karl-Marx-Stadt (la actual Chemnitza)—, su apoyo caería por debajo del 35\% en Frankfurt am Oder y en Potsdam, derrumbándose en Berlín hasta el 21,5\%. Al contrario, el SPD y el PDS lograrían sus mejores resul- 
tados en la capital, donde alcanzarían respectivamente el 34,9 y el $30,2 \%$ de los votos, y en núcleos como Rostock o los mencionados de Frankfurt y Potsdam. Los liberales, con un $5,28 \%$ de los votos, se situarían en una geografía similar a la de los democristianos, siendo reseñable su $10 \%$ en Halle, lugar de origen de su líder nacional.

A la vista de tales resultados, resultaba evidente que el SPD había fracasado en su intento de captar la mayor parte del voto obrero -masivamente situado en las zonas industrializadas del sur-, mientras que los democristianos sí habian tenido éxito a la hora de transmitir su mensaje de fiabilidad para la transición. Se hacía, pues, inevitable un gobierno democristiano, que además presentaría la ventaja de la sintonía con el ya situado en Bonn. Sin embargo, la necesidad de hallar el máximo grado de consenso en cuantas decisiones fuesen a tomarse en el futuro aconsejaría al líder democristiano De Maizière ampliar cuanto fuese posible la base parlamentaria de su gobierno. De este modo, el primer gabinete en salir de las elecciones se hallaría integrado por 15 ministros de la Alianza por Alemania, 6 del SPD y 3 liberales.

Por lo que respecta a las elecciones municipales, su celebración en el mes de mayo de 1990, apenas dos meses después de las parlamentarias, propiciaría una sustancial coincidencia de resultados entre éstas y aquéllas. Descenderían la CDU, que repetiría triunfo pero disminuiría su apoyo electoral hasta el $34,4 \%$ de los sufragios; su socio de coalición, la DSU, que se habría de conformar con apenas un $3,4 \%$, y el PDS, que descendería hasta el $14,6 \%$. Los socialdemócratas, sin embargo, apenas se moverían, quedando con un $21,3 \%$ de los votos. Por último, mejorarian sus resultados los liberales del BFD, que llegarían hasta un estimable $67 \%$. El Nuevo Foro concurriría en la mayoría de los distritos en solitario, consiguiendo unos resultados un tanto más bajos -el 2,4\%- de los cosechados en las generales por la coalición Bündnis 90. La tasa de participación, situada en torno a 75\%, sería un elemento más de estabilidad política puesto que, aunque inferior a la de las elecciones generales, no denotaba en modo alguno los síntomas de desconfianza y desilusión que otros países ya estaban comenzando a padecer.

\section{BULGARIA: RALENTIZAR EL CAMBIO}

El proceso de transición política en Bulgaria tendría su más significativo punto de partida en la sustitución, el 10 de noviembre de 1989, del casi octogenario Todor Jivkov, en el poder desde 1971, por uno de sus más destacados delfines, el entonces Ministro de Asuntos Exteriores 
Petar Mladenov. El relevo, que había sido auspiciado tanto por el ejército como por el partido, tenía como objetivo fundamental anticiparse a los previsibles movimientos de masas que, siguiendo el ejemplo germanooriental o húngaro, era previsible que apareciesen de inmediato también en Bulgaria. Colocando en la cúspide de la jerarquía del Estado y del partido a un líder un tanto más aperturista, parecía apostarse por una transición más «a la húngara», esto es, por un proceso de cambio mucho más lento, en el que el partido no perdiese en ningún momento el control de la situación y del que pudiera derivarse, en el peor de los casos, una limitada liberalización en la que al partido le seguiría correspondiendo una situación de privilegio. Aun así, la convocatoria de unas elecciones libres y competitivas no tardaría demasiado en plantearse, de modo que ya en el mes de enero de 1990 el nuevo gobierno se vería forzado a entrar en una serie de conversaciones con las principales fuerzas de la naciente oposición para, como en había ocurrido en Polonia y Hungría, negociar el momento y el modo en el que habría de celebrarse la mencionada consulta.

En el momento de la caída de Jivkov, el panorama de las fuerzas opositoras era más bien caótico. La única organización legalizada al margen del Partido Comunista era en aquel momento la Unión Agraria Nacional Búlgara, que después de haber sido en el periodo de entreguerras la más importante fuerza política del país había venido jugando desde el fin de la II Guerra Mundial el papel de partido satélite del comunista. Disueltas sus organizaciones juveniles, y limitado artificialmente el número de sus afiliados, su papel se reducía a proporcionar al sistema un cierto número de cuadros políticos intermedios. La oposición ilegal, por su parte, se hallaba enormemente fragmentada y poco estructurada, agrupándose fundamentalmente en base a dos diferentes reivindicaciones: la ecologista, defendida por el grupo Ecoglasnost, y la de carácter étnico, concretada en los grupos de defensa de la minoría turca Liga Democrática y Grupo de Iniciativa Musulmana.

Tales fuerzas no representarían una amenaza seria frente al poder establecido hasta que el 7 de diciembre fuese constituida la Unión de Fuerzas Democráticas (SDS). En tal coalición convergerían inicialmente un total de nueve grupos opositores, entre los que se hallaban Ecoglasnost y el sindicato independiente Podkrepa, verificándose poco después la integración de otras siete organizaciones políticas y ecologistas que constituirían así la más relevante fuerza opositora, eligiendo al conocido filósofo disidente Jeliu Jelev como presidente. Por su parte, la minoría turca preferiría conformar una fuerza políticamente autónoma, propiciando la creación del Movimiento por los Derechos y las Libertades. Bajo el liderazgo del también filósofo Mehmet Dogan, este grupo presentaría un programa político fundamentalmente orientado a la defensa de la identi- 
dad cultural turca y al estrechamiento de los vínculos políticos con la república vecina, lo cual no dejaría de ocasionar algunas tensiones con los sectores más decididamente nacionalistas del país. Por último, el Partido Comunista Búlgaro celebraría a finales de enero su XIV Congreso, procediendo a un importante cambio de imagen que comprendería incluso la adopción de una nueva denominación -Partido Socialista Búlgaro (BSP)—, si bien no la disolución de la antigua formación comunista ni la dispersión de su patrimonio. Al frente del "nuevo" partido quedaría Alexandre Lilov, retirándose así Petar Mladenov - que tras la pertinente reforma constitucional resultaría elegido Presidente de la República- de toda actividad partidista.

La convocatoria de las prometidas elecciones parlamentarias se acordaría, después de más de dos meses de tensas negociaciones, el 30 de marzo de 1990. El acuerdo entre el gobierno y las fuerzas opositoras, que sería ratificado sin problemas por el Parlamento aún operante, preveía la elección de una Asamblea constituyente - la Gran Asamblea Nacional- compuesta por 400 parlamentarios, que tendría como misión principal la de elaborar una nueva Constitución, por más que su posterior disolución quedase al arbitrio de la propia Cámara. La elección habría de verificarse en dos vueltas, el 10 y el 17 de junio de 1990, en una fecha excesivemente temprana para la oposición, que continuamente había abogado por una postergación de la consulta que le permitiese acudir a la misma con un aparato organizativo un tanto más desarrollado. El sistema electoral -la cuestión más polémica de las planteadas- resultaría ser un sistema mixto entre proporcional y mayoritario. Así, la mitad de los escaños en juego se disputarían sobre la base de distritos uninominales por un sistema electoral de mayoría absoluta a dos vueltas, disputándose la otra mitad por un sistema proporcional y de lista sobre la base de las tradicionales 28 provincias búlgaras, quedando en este segundo caso excluidos del reparto los partido que no lograsen al menos el $4 \%$ de los votos a nivel nacional.

El sistema electoral ideado combinaba en teoría las aspiraciones de gobierno y oposición, interesado el primero en prolongar la vigencia del viejo sistema mayoritario y el segundo en sustituirlo por uno enteramente proporcional. Pero en la realidad, la opción no hacía sino favorecer las posiciones del PSB, que, tras una campaña plena de incidentes de todo tipo, conseguiría imponer su mejor organización y sus mayores medios y sacarle todo el partido a un sistema electoral hecho casi a su medida.

Los resultados electorales (véase cuadro II) proporcionarían al BSP una holgada mayoría absoluta, cimentada, ciertamente, en un porcentaje de votos altamente significativo. Por su parte, la SDS se consolidaría 


\section{Cuadro II \\ BULGARIA \\ Elecciones parlamentarias}

1. ${ }^{\text {a Vuelta: }} 10$ de junio de 1990. 2. ${ }^{\text {a Vuelta: }} 17$ de junio de 1990 Participación: 1. ${ }^{a}$ Vuelta: 6.334 .415 electores (90,79\%)

Gran Asamblea Nacional (Veliko Narodno Sbranie): 400 escaños

\begin{tabular}{|c|c|c|c|c|c|}
\hline & $\begin{array}{c}N .9 \\
\text { votos }\end{array}$ & $\begin{array}{c}\% \\
\text { votos }\end{array}$ & $\begin{array}{l}\text { Repr. } \\
\text { Prop. }\end{array}$ & $\begin{array}{l}\text { Repr. } \\
\text { May. }\end{array}$ & $\begin{array}{l}\text { Esc. } \\
\text { Total }\end{array}$ \\
\hline BSP (Partido Socialista Búlgaro) ............ & 2.887.766 & 47,1 & 97 & 114 & 211 \\
\hline $\begin{array}{l}\text { SDS (Unión de Fuerzas Democráticas). } \\
\text { DPS (Mov. por los Derechos y las }\end{array}$ & 2.317 .798 & 36,2 & 75 & 69 & 144 \\
\hline Libertades) & 368.929 & 6,0 & 12 & 11 & 23 \\
\hline \multicolumn{6}{|l|}{ BZNS (Unión Nacional Agraria } \\
\hline Búlgara) & 491.597 & 8,0 & 16 & 0 & 16 \\
\hline Partido Patriótico del Trabajo.................. & 36.668 & 0,6 & - & 1 & 1 \\
\hline BSDP (Partido Socialdemócrata) ............. & 3.036 & 0,05 & - & 1 & 1 \\
\hline 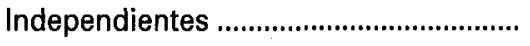 & - & - & - & 4 & 4 \\
\hline
\end{tabular}

como el gran partido de la oposición, relegando al Movimiento para los Derechos y las Libertades y a la Unión Agraria Nacional a un discreto segundo plano. Más aún, el apoyo que estos grupos darían a los candidatos de la SDS para la segunda vuelta les colocaría -especialmente en el caso de los agrarios- en situación de ser a medio plazo absorbidos por ésta. Si a ello le añadimos el hecho de que la barrera del $4 \%$ impidió el acceso a la Cámara de forma significativa al resto de las fuerza concurrentes, habremos de concluir la existencia en el sistema de partidos búlgaro de una tendencia clara hacia el bipartidismo, contradictoria - por cierto- con la del resto de los países de su entorno.

Por lo que respecta a la implantación territorial de las distintas fuerzas concurrentes, podría afirmarse - simplificando un tanto los términos- que mientras el Partido Socialista conseguiría el respaldo de los distritos rurales, la SDS haría lo propio en las grandes ciudades -en Sofia ganó en 24 de los 26 distritos, obteniendo resultados similares en Plovdiv y Varna-, defendiéndose igualmente en los grandes núcleos industriales. EI DPS, lógicamente, concentraría sus éxitos en el sureste del país, en donde se concentra la mayor parte de la población étnicamente turca, lo que nos acabaría propiciando un mapa político bien similar al que unos días antes habían arrojado las elecciones rumanas: un partido socialista reformado implantado en las grandes áreas rurales, una oposición democrática reducida a las grandes ciudades y una minoría étnica confinada a los territorios de los que es propia. 
Con todo, los resultados electorales se revelarían bien pronto como poco representativos de la auténtica realidad política búlgara. Forzada la dimisión de Mladenov a causa de la difusión de unas declaraciones suyas de diciembre del año anterior en las que abogaba inequívocamente por una intervención militar, los socialistas se verían incapaces de obtener de la Asamblea Nacional los 2/3 de votos necesarios para investir a su candidato presidencial, habiendo de recaer finalmente el cargo en el líder opositor Jelev. Más tarde, la imponente cadena de manifestaciones y huelgas que la oposición organizaría en noviembre y diciembre de 1990, acabaría forzando la dimisión del Primer Ministro socialista Lukanov, y su sustitución por el independiente Popov al frente de un gobierno de unidad nacional. La Asamblea Nacional, surgida de unos comicios como mínimo poco transparentes, se vería así incapaz para sostener a un gobierno que la realidad parecía superar por momentos.

\section{LAS REPÚBLICAS CHECA Y ESLOVACA: RESTAURAR LA DEMOCRACIA Y REPLANTEAR EL FEDERALISMO}

El proceso de normalización democrática en Checoslovaquia -lo que se ha dado en llamar "la Revolución de Terciopelo»- revestiria respecto del experimentado en otros paises una especial complejidad, toda vez que, apenas sentadas las primeras bases para la plena recuperación de las libertades civiles y políticas de los checos y los eslovacos, saltaría a la palestra la necesidad de reestructurar radicalmente las bases sobre las que había sido edificada la convivencia entre estas dos naciones durante la etapa comunista. De este modo se le añadiría al ya complejo proceso de institucionalización democrática la dificultad de una simultánea reestructuración del modelo federal, insatisfactorio tanto para unos como para otros. Tal fenómeno marcaría hondamente los procesos electorales vividos durante 1990, configurando un muy peculiar sistema de partidos que, al evolucionar con el paso del tiempo, lo haria hacia la diversificación y no hacia la homogeneidad.

Las elecciones checoslovacas del 8 de junio de 1990 presentarían respecto de la inmensa mayoría de los procesos electorales de este año una particularidad: la de que su convocatoria, su regulación y su materialización se llevarían a cabo no bajo el mandato de las últimos dirigentes comunistas sino bajo la autoridad de los antiguos opositores convertidos en nuevos gobernantes.

En efecto: las manifestaciones populares, que a mediados de noviembre marcarían el inicio del proceso de cambio, forzarian pocos días 
después la sustitución del gobierno comunista de Ladislav Adamec por un gobierno de amplia base liderado por Marián Calfa, comunista igualmente pero más proclive a la cohabitación con las fuerzas opositoras. En tal gobierno, el Partido Comunista Checoslovaco no retendría más que 9 de las 20 carteras. El relevo en la Jefatura del Estado se produciría el 29 de diciembre, con la investidura como Presidente del conocido dramaturgo y disidente Václav Havel. El relevo en la Asamblea Federal, así como en los Consejos Nacionales tanto de la República Checa como de la Eslovaca, tampoco se haría esperar, $y$, aun antes de celebradas las elecciones, el Partido Comunista se encontraría en minoría en las tres Cámaras como resultado de una intensa campaña de depuración que empujaría a un gran número de parlamentarios comunistas a dejar el partido o a abandonar la Cámara, para ser sustituidos provisionalmente por representantes de la oposición. La elección de Alexandr Dubcek como Presidente de la Asamblea Federal constituiría todo un símbolo de lo que estaba ocurriendo.

Así las cosas, no es de extrañar que el proceso electoral checoslovaco resultase auténticamente ejemplar, perfectamente homologable en cuanto a sus garantías con cualquiera de los que habitualmente pudieran contemplarse en las democracias más consolidadas.

El momento y el modo de celebración de los comicios se decidiría, como casi todas las medidas de importancia que se adoptasen en el primer semestre de 1990, en el marco de las negociaciones que las autoridades comunistas y las fuerzas opositoras mantendrían desde el comienzo de las movilizaciones de noviembre hasta prácticamente la constitución de las nuevas Cámaras. A falta de un Parlamento realmente representativo, la "Mesa Redonda" se convertiría en el auténtico foro de negociación y debate del país, foro en el que la fuerza de las distintas partes negociadoras evolucionaría conforme variasen su predicamento en la sociedad y sus perspectivas electorales.

El primer objeto de discusión se plantearía en torno a la estructura de las futuras Cámaras representativas. Parecía evidente la necesidad de que el Parlamento Federal siguiese constituido sobre la base de dos Cámaras, una representativa de la población - y por lo tanto con una mayoría de escaños para la República Checa, de mayor peso demográficoy otra representativa de los territorios del Estado, compuesta a partes iguales por parlamentarios checos y eslovacos. Además, resultaba imprescindible la supervivencia de los Consejos de cada una de las dos Repúblicas, con lo que finalmente se llegaba a la constitución de cuatro Cámaras que reunian en conjunto 700 diputados. Para evitar una proliferación innecesaria de órganos representativos se sugeriría que los Consejos checo y eslovaco se formasen con igual número de miembros, de 
forma que pudieran actuar conjuntamente como Cámara Alta, obviando así la existencia de un órgano superfluo. Pero las excesivas sensibilidades de unos y otros y la necesidad de hallar soluciones rápidas darían al traste con la idea, acordándose tan sólo una reducción del número de componentes de la Cámara Baja. Así, el 8 de junio habrían de elegirse simultáneamente los 150 miembros de la Cámara del Pueblo - de los que 101 serían elegidos por los 7,5 millones de checos, y los restantes 49 por los 3,6 millones de eslovacos-, los 150 miembros de la Cámara de las Naciones -elegidos a partes iguales por ambos territorios-, los $200 \mathrm{di}$ putados del Consejo Nacional Checo y finalmente los 150 del Consejo $\mathrm{Na}$ cional Eslovaco.

Ante tal complejidad, el sistema electoral elegido tenía que ser forzosamente uno de gran sencillez. $Y$ dada la creciente proliferación de fuerzas políticas de todo cuño, parecía claro que debía de tratarse de uno proporcional y de lista. La Ley Electoral, aprobada por la Asamblea Federal el 27 de febrero, contemplaría ambos extremos, si bien con matices. El sistema electoral diseñado sería así un sistema proporcional y de lista, sobre la base de las doce provincias preexistentes -ocho en territorio checo y cuatro en territorio eslovaco-, en el que para concurrir los partidos y coaliciones debían acreditar el contar al menos con 10.000 afiliados o presentar en su defecto igual número de firmas. Además, para entrar en el reparto de escaños era preciso haber obtenido al menos un $5 \%$ de los votos emitidos en cualquiera de las dos Repúblicas (para el Consejo Nacional Eslovaco se acordaría rebajar el porcentaje al $3 \%$ ), con lo que el peligro de una excesiva fragmentación de las Cámaras quedaría en teoría conjurado. Por último, la ley complicaría un tanto la mecánica electoral, introduciendo una especie de voto preferencial cualificado. Así, el elector dispondría de hasta cuatro preferencias a otorgar entre los distintos candidatos de la lista del partido escogido; sin embargo, éstas sólo serían contabilizadas cuando al menos un $10 \%$ de los votantes hubiesen hecho uso de ellas, y sólo en beneficio de aquellos candidatos que hubiesen obtenido al menos la mitad de las preferencias emitidas. El sistema resultaría, por lo tanto, menos sencillo y menos proporcional de lo previsto en un principio, pero cumpliria sobradamente con su misión: facilitar una elevada participación y reducir significativamente el número de los componentes de la escena política checoslovaca.

Tal escena política resultaría casi desde el primer momento la más compleja, con mucho, del antiguo mundo comunista. Sería por tanto forzoso distinguir, de una parte, entre las organizaciones políticas "históricas" - esto es, anteriores al advenimiento del régimen de partido únicoy las de nuevo cuño, aparecidas tras la "Revolución de Terciopelo". Pero, por otra parte, se impondría también distinguir entre las organizaciones 
de ámbito estatal y las asentadas únicamente en una de las dos Repúblicas, complicándose aún más la cuestión por el hecho de que de entre estas últimas formaciones se encontrasen grupos de carácter nacionalista pero también grupos coordinados con otros en la otra República, con lo que, más que de partidos autonomistas, habría que hablar en este último caso de distintas secciones de un mismo movimiento.

Entre los partidos que podríamos llamar "históricos" habría que mencionar al Partido Socialista Checoslovaco (CSS) y a la Socialdemocracia Checoslovaca (CSSD), protagonistas ambos de la interesante experiencia democrática de la Checoslovaquia de entreguerras. Un tercer partido histórico, el Partido Popular (CSL), se integraría, junto con el Partido Cristiano-Demócrata (KDS), de Václav Benda, en la Unión Cristiana y Democrática (KDU), coalición en este caso de ámbito exclusivamente checo. El Partido Comunista Checoslovaco (KSCS), profundamente reestructurado después de su congreso extraordinario de diciembre de 1989, afrontaría los comicios bajo la dirección de Ladislav Adamec y Vasil Mohorita, si bien renunciaría a alterar su denominación como habían hecho la mayor parte de los partidos comunistas en otros países del entorno. Por último, el Partido Demócrata (DS), de ámbito exclusivamente eslovaco, reclamaría para sí la herencia del partido que con el mismo nombre había arrollado en Eslovaquia durante las últimas elecciones libres de 1946, por más que su larga trayectoria de condescendencia con el comunismo obligaba a mirar con escepticismo tal pretensión.

Con todo, la mayor parte de los 22 partidos y coaliciones que a la postre acabarian presentándose a las elecciones serían fuerzas de nuevo cuño, fundadas al abrigo de las nuevas tendencias democratizadoras. De entre ellas, las de mayor entidad serían sin duda el Foro Cívico (OF), fundado en Praga el 19 de noviembre y asentado tan sólo en la República Checa, y Público Contra la Violencia (VPN), su homólogo eslovaco, fundado pocos días después en Bratislava. Ambas entidades tenían a su favor el hecho de ser las más directas herederas del prestigioso movimiento disidente Carta 77, y de contar entre sus dirigentes con los dos líderes más prestigiosos del momento: Václav Havel y Alexandr Dubcek. Además, tanto el Foro Cívico como el VPN habían conseguido labrarse en poco tiempo una inestimable autoridad moral en el seno de los movimientos opositores, bien fuese por causa de la larga trayectoria de disidencia y cárcel de muchos de sus miembros, bien fuese por su empeño en no aparecer como un partido político más, sino como un amplio movimiento de masas e intelectuales siempre abierto al debate. Por esta causa, ambas fuerzas partirían como favoritas en sus respectivos ámbitos de cara a la contienda electoral, al tiempo que disfrutarían ya desde diciembre de una privilegiada posición en el gobierno de coalición de Calfa. 
Paralelamente, la opción democristiana, que en la República Checa había venido encarnada por la KDU, alcanzaría un acuerdo con el Movimiento Cristianodemócrata (KDH), asentado en Eslovaquia, por el que ambas entidades se limitarían mutuamente en su ámbito territorial cooperando en las cuestiones de relevancia estatal.

El cada vez más pujante nacionalismo eslovaco se encarnaría en el Partido Nacional Eslovaco (SNS), de tendencia radical y próximo a las reivindicaciones separatistas de un sector del electorado eslovaco. Por su parte, la Sociedad para Moravia y Silesia plantearía nuevos problemas a la siempre problemática integridad estatal checoslovaca, al reivindicar para estos territorios del centro del país una mayor autonomía respecto de Praga y una igualdad de trato en el futuro modelo federal. Frente a estas tendencias centrifugas, otras formaciones como el Movimiento para el Entendimiento Checoslovaco harían especial hincapié en los factores de cohesión entre los distintos integrantes del Estado checoslovaco, si bien su éxito resultaría escaso.

En última instancia, a la contienda electoral acudirían un largo número de "single issue parties". Entre ellos se hallarían -baste mencionarlos - la Alianza Campesina, el Partido Verde, la Alianza Electoral de Grupos de Interés de la República Checa, el grupo Gitanos o el Partido de los Amigos de la Cerveza. De entre todos ellos sólo la coalición entre el grupo Coexistencia y el Movimiento Húngaro Cristiano Demócrata alcanzaría cierta relevancia, al obtener un significativo apoyo de la poderosa minoría húngara de Eslovaquia en su reivindicación de unas mejores relaciones interétnicas.

La campaña electoral resultaría, como en tantas otras partes, caótica y un tanto tediosa. Ante semejante cúmulo de contendientes, y sin que existiesen criterios que permitiesen dar preferencia a unos sobre otros en el uso de los medios públicos de comunicación, los electores asistirian atónitos a interminables sesiones propagandísticas de las que apenas era posible sacar alguna deducción somera respecto de las particularidades programáticas de cada uno de los contendientes. De hecho, una buena parte de éstos no presentarían ante sus electores sino vagas alusiones a la necesidad de modernizar la economía del país, de introducir la libre empresa y de recuperar las libertades, lo cual forzaria a algún comentarista a argumentar que los programas de los partidos eran entre sí tan similares como un guisante a otro guisante.

En cualquiera de los casos, nada de ello conseguiría desanimar a los electores, que acudirían masivamente a las urnas, alcanzando nada menos que un porcentaje de participación del $96 \%$. 
El escrutinio posterior (véanse cuadros III y IV) otorgaría al Foro Cívico y a Público Contra la Violencia un triunfo inapelable aunque desigual, pues si el primero conseguía en la República Checa porcentajes que rondaban y aun superaban - según las Cámaras-el $50 \%$ de los votos, el segundo, aun siendo la fuerza mayoritaria en la República Eslovaca, no conseguía superar el $37 \%$ de los votos, quedando con apenas el $30 \%$ en el Consejo Nacional Eslovaco. Por su parte, los comunistas obtendrían un resultado respetable, colocándose, con algo más del $13 \%$ de los votos, como segunda fuerza del país, si bien a una enorme distancia de la alianza OFNPN. Los democristianos sumarían una cantidad casi idéntica de votos en cada una de las dos Repúblicas, aunque su potencia relativa resultaría mucho más importante en su feudo tradicional de Eslovaquia, donde se revelarían como segundo partido. En la misma Eslovaquia el SNS lograria un respetable $11 \%$ de los votos, que subiría hasta casi el $14 \%$ en la elección del Consejo Nacional Eslovaco, mientras que los autonomistas moravos tendrían que conformarse en la República Checa con porcentajes en torno al $9 \%$. Por último, los húngaros de Coexistencia-MKDH, con casi $\mathbf{3 0 0 . 0 0 0 ~ s u f r a g i o s , ~ o b t e n d r i ́ a n ~ u n ~ p o r c e n t a j e ~ d e ~ v o t o s ~}$ de un $8,5 \%$ en Eslovaquia, quedando como fuerza meramente testimonial en la otra mitad del país.

En términos generales, los resultados acabarían siendo mejores de lo previsto para el Foro Cívico, para los comunistas - a los que no se les daba más que un $10 \%$ de los votos- y para los nacionalistas del SNS, constituyendo una auténtica sorpresa el resultado de la Sociedad por Moravia y Silesia. Por contra, los democristianos verían insatisfechas sus aspiraciones de vencer en Eslovaquia, al tiempo que eran prácticamente barridas todas las llamadas formaciones históricas, sin duda demasiado ligadas con el pasado como para resultar atractivas en el presente. El subsiguiente reparto de escaños brindaría a la coalición OFNPN una holgada mayoría absoluta en las dos Cámaras del Parlamento Federal, así como en el Consejo Nacional Checo, pero les dejaría en minoría en el Consejo Nacional Eslovaco. Tal situación forzaría un gobierno de coalición con los democristianos en esta última República, solución que se revelaría como interesante también a nivel federal, toda vez que la incorporación de la poderosa Democracia Cristiana eslovaca a la mayoría gubernamental pondría al alcance de ésta la mayoría de $3 / 5$ necesaria para llevar a cabo reformas constitucionales, al tiempo que brindaría al gobierno federal una mayor legitimidad en sus siempre problemáticas relaciones con los eslovacos. Como Presidente de la República sería elegido nuevamente Václav Havel, quedando al frente del Gobierno el hasta entonces Primer Ministro Marián Calfa, dando así por buẹna la práctica de que si el Presidente de la República era checo - caso de Havel-, el del Gobierno había de ser eslovaco. 


\section{Cuadro III \\ REPÚBLICA FEDERATIVA CHECA Y ESLOVACA \\ Elecciones parlamentarias \\ 8 y 9 de junio de 1990}

Participación: 96,79\% en la República Checa, 95,41\% en la República Eslovaca

Cámara del Pueblo (Snemovna Národu FS): 150 escaños (101 para la República Checa y 49 para la Eslovaca)

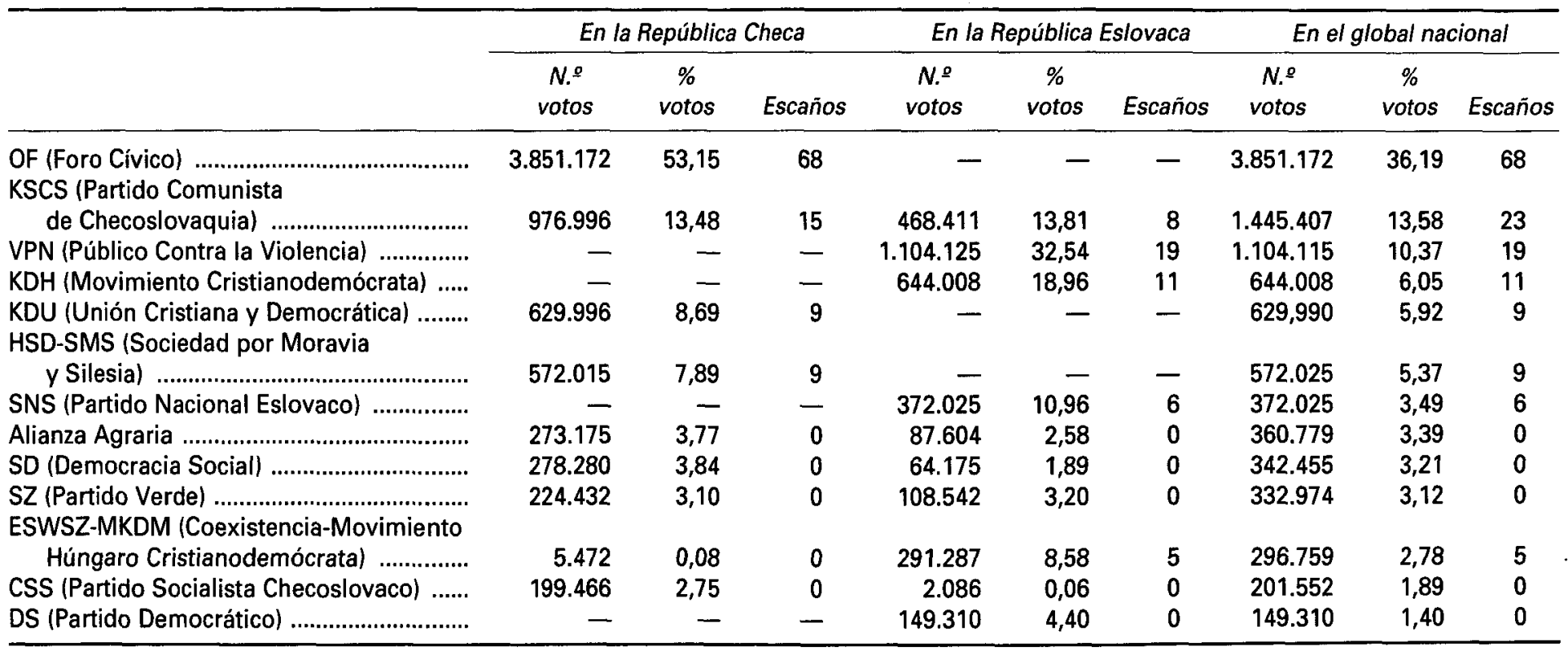




\section{Cuadro IV \\ REPÚBLICA FEDERATIVA CHECA Y ESLOVACA \\ Elecciones parlamentarias}

Cámara de las Naciones (Snemovna Lidu FS):

150 escaños (75 para la República Checa y 75 para la Eslovaca)

\begin{tabular}{lrrrrr}
\hline & \multicolumn{3}{c}{ República Checa } & \multicolumn{2}{c}{ República Eslovaca } \\
\cline { 2 - 6 } & $\%$ votos & Escaños & $\%$ votos & Escaños \\
\hline OF (Foro Cívico) .............................................. & 49,96 & 50 & - & - \\
KSCS (Partido Comunista Checoslovaco)...... & 13,80 & 12 & 13,43 & 16 \\
VPN (Público Contra la Violencia) .................. & - & - & 37,28 & 33 \\
KDH (Movimiento Cristianodemócrata) ........... & - & - & 16,66 & 14 \\
KDU (Unión Cristiana y Democrática)............ & 8,75 & 6 & - & - \\
HSD-SMS (Sociedad por Moravia y Silesia). & 9,10 & 7 & - & - \\
SNS (Partido Nacional Eslovaco) ................... & - & - & 11,44 & 9 \\
Coexistencia-Mov. Húngaro Cristiano Dem. . & - & - & 8,49 & 7 \\
\hline
\end{tabular}

Consejo Nacional Checo (Ceské Národná Rada): 200 escaños

\begin{tabular}{|c|c|c|}
\hline & $\%$ votos & Escaños \\
\hline OF (Foro Cívico) .. & 49,50 & 127 \\
\hline KSCM (Partido Comunista de la República Checa)... & 13,24 & 16 \\
\hline 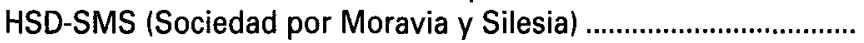 & 10,03 & 22 \\
\hline KDU (Unión Cristiana y Democrática) & 8,42 & 19 \\
\hline 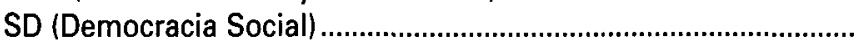 & 4,11 & 0 \\
\hline SZV (Alianza Agraria) & 4,11 & 0 \\
\hline SZ (Partido Verde) & 4,10 & 0 \\
\hline
\end{tabular}

Consejo Nacional Eslovaco (Slovenská Národná Rada): 150 escaños

\begin{tabular}{|c|c|c|}
\hline & $\%$ votos & Escaños \\
\hline VPN (Público Contra la Violencia) ..................... & 29,34 & 48 \\
\hline KDH (Movimiento Cristianodemócrata) ............ & 19,20 & 31 \\
\hline 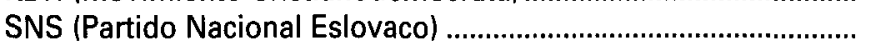 & 13,94 & 22 \\
\hline 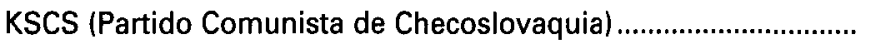 & 13,34 & 22 \\
\hline ESWSZ-MKDM (Coexistencia-Mov. Húngaro Crist. Demócrata)... & 8,66 & 14 \\
\hline DS (Partido Democrático) & 4,39 & 7 \\
\hline SZ (Partido Verde) & 3,48 & 6 \\
\hline 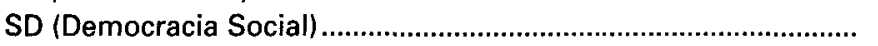 & 1,81 & 0 \\
\hline
\end{tabular}


Como conclusión, entiendo que los resultados de las elecciones parlamentarias checoslovacas de junio de 1990 permiten formular cuando menos tres consideraciones.

En primer lugar, la de que en el electorado checoslovaco se verificó la tendencia - tan típica de los momentos de transición de un sistema político a otro- de concentrar el voto en las opciones políticas que a priori parecen mayoritarias, en especial cuando éstas tienen contornos ideológicos poco perfilados y presentan como principal reivindicación política la ruptura con el pasado. Tal tendencia, sin embargo, estaría llamada a dejar paso no bien se hubiese producido una cierta normalización democrática, a una tendencia contraria, por lo que resultaba previsible en el inmediato futuro una recomposición en profundidad del panorama político checoslovaco, en especial en el ámbito inicialmente cubierto por la coalición OF/NPN. Tal recomposición comenzaría a gestarse a comienzos de 1991, cuando, tras el congreso del Foro Cívico en el que esta formación decidiera su constitución en partido político, se produjese su fraccionamiento en tres fuerzas: el Partido Demócrata Cívico de Václav Klaus (ODS), mayoritario y de centro-derecha: el Movimiento Cívico $(\mathrm{OH})$ de Jiri Dienstbier, Petr Pithart y Pavel Rychetsky, menos numeroso pero con un mayor porcentaje de cargos representativos y situado en el centro-izquierda, y la Alianza Cívica Democrática (ODA) de Pavel Bratinka y Vladimir Dlouhy. En este proceso quedarían descolgados un buen número de diputados, varios de los cuales acabarían decantándose por el Partido Socialdemócrata, que de este modo alcanzaría representación parlamentaria. En Público Contra la Violencia, la ruptura se produciría en marzo, al fundar el entonces Primer Ministro eslovaco, Vladimir Meciar, el Movimiento por una Eslovaquia Democrática (HZDS), operación que terminaría de arrojar al VPN y al propio gobierno eslovaco en manos del Movimiento Cristianodemócrata de Jan Carnogurski, que por su parte no tardaría en radicalizar su mensaje nacionalista.

En segundo lugar, la de que, casi desde el primer momento, aparecerian en Checoslovaquia importantísimas tendencias centrífugas, tendencias que si bien se desarrollaron con preferencia en Eslovaquia, no se haIlaron tampoco ausentes de la escena política checa. Ello debe constituir sin duda un importante objeto de reflexión, toda vez que una inadecuada solución al problema de la convivencia entre checos y eslovacos, pero también entre bohemios, moravos, silesios, húngaros o gitanos, sin duda se halla en la raíz de la desaparición de Checoslovaquia como Estado, e incluso del deterioro de la estabilidad interna de los Estados resultantes.

Y en tercer lugar, la de que, al margen de las citadas tendencias centrífugas, sería un hecho la consolidación de distintos sistemas de partidos en una y otra República. No sólo es que existiesen significativas fuer- 
zas separatistas, o que los eslovacos hubiesen optado por una línea política más conservadora y nacionalista, mientras que los checos preferian formaciones de talante más laico y de impronta más federalista. Es que incluso mensajes en principio idénticos, como los planteados por el Foro Cívico y VPN o por los democristianos de una y otra República, acabarian hechos añicos merced a las exigencias diferenciadoras de unos y otros. Como dato significativo, podría aducirse el de que solamente una de las fuerzas políticamante relevantes del país -el Partido Comunista - aceptaría acudir a los comicios con idénticos signos de identidad en una una y otra República. Pocos meses después de las elecciones, ni siquiera este recuerdo del pasado unitarismo checoslovaco permanecería vigente.

Así las cosas, las elecciones locales del 23 y el 24 de noviembre de 1990 no harían sino confirmar las referidas tendencias hacia la dispersión. En la República Checa, el Foro Cívico, que había desarrollado con anterioridad a la campaña una amplia política de alianzas con fuerzas a su izquierda, acabaría perdiendo una parte importante de su electorado, quedando con un $35 \%$ de los votos. Tales pérdidas serían recogidas en parte por los democristianos del CSL, que subirían hasta el 11,5\%, mejorando también sus resultados los comunistas - nuevamente renovados tras la sustitución de Adamec por Pavel Kanis-, que acabarían alcanzando un preocupante $17 \%$ de los votos. En Eslovaquia, el Movimiento Cristianodemócrata superaría ampliamente sus resultados de las generales, consiguiendo en torno al $27 \%$ de los votos, frente al $20 \%$ del Público Contra la Violencia, que se hundía, víctima de sus disensiones internas y del desgaste propio del gobierno. Por su parte, tanto los independentistas eslovacos como los autonomistas moravos y silesios experimentarían importantes descensos, que en el caso del SNS dejaría al partido con la cuarta parte del porcentaje cosechado en junio. Por contra, las candidaturas municipales independientes, muy numerosas, cosecharian por todo el país numerosos éxitos.

Las elecciones municipales supondrían primeramente (véase cuadro V) un duro golpe para la coalición gubernamental OFNPN: el partido de Havel perdería entre 14 y 18 puntos, mientras que su aliado eslovaco quedaba entre 9 y 17 puntos por detrás de los resultados logrados en las distintas elecciones de junio. Pero, sobre todo, supondrían el comienzo definitivo del imparable proceso de fragmentación de las fuerzas políticas que habian llevado a cabo en las dos Repúblicas la llamada "Revolución de Terciopelo». Las importantes pérdidas de la coalición gobernante, el acceso a los gobiernos locales de numerosas fuerzas que no habían conseguido escaños parlamentarios $y$, sobre todo, el importante resultado de las candidaturas independientes, constituirían los primeros síntomas de un proceso de descomposición que llenaría todo el año 1991 y que en 1992 abocaría al país a la ruptura. 


\section{Cuadro V \\ REPÚBLICA FEDERATIVA CHECA Y ESLOVACA \\ Elecciones municipales \\ 23 y 24 de noviembre de 1990}

Participación: $73,5 \%$ en la República Checa, $63,7 \%$ en la República Eslovaca

\begin{tabular}{|c|c|c|c|c|}
\hline & \multicolumn{2}{|c|}{ República Checa } & \multicolumn{2}{|c|}{ República Eslovaca } \\
\hline & $\%$ votos & Escaños & $\%$ votos & Escaños \\
\hline OF (Foro Cívico) & 35,5 & 31,6 & - & 一 \\
\hline KSCM/KSS-SDL (Partido Comunista) ................... & 17,4 & 15,8 & 14 & 13,6 \\
\hline CSL (Partido Popular Checoslovaco).................. & 21,1 & 15,8 & - & - \\
\hline CSSD (Social Democracia Checa)..................... & 5,0 & 1,2 & - & - \\
\hline SMS (Sociedad por Moravia y Silesia) ........... & 4,7 & 2,0 & - & - \\
\hline CSS (Partido Socialista Checoslovaco) ............ & 3,8 & 1,0 & - & - \\
\hline 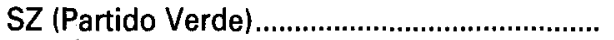 & 2,7 & 0,6 & - & - \\
\hline 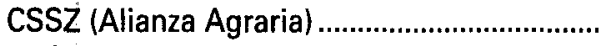 & 1,9 & 4,7 & - & - \\
\hline KDS (Partido DemócrataCristiano) ................... & 1,0 & 0,1 & - & - \\
\hline KDH (Movimiento Cristianodemócrata) .......... & - & 一 & 27 & 27,4 \\
\hline VPN (Público Contra la Violencia) .................... & - & 一 & 20 & 20,4 \\
\hline 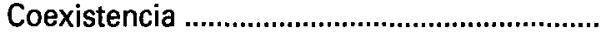 & - & - & - & 6,3 \\
\hline SNS (Partido Nacional Eslovaco) ......................... & - & - & 3 & 3,2 \\
\hline Movimiento Húngaro Cristiano Demócrata... & - & - & - & 3,0 \\
\hline 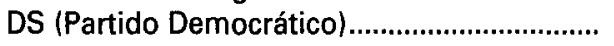 & - & - & - & 2,3 \\
\hline Otros & 6,4 & 3,5 & - & 7,9 \\
\hline Independientes & 10,5 & 26,6 & - & 12,8 \\
\hline
\end{tabular}

\section{HUNGRÍA: UNA TRANSICIÓN ORDENADA}

El proceso de transición hacia la democracia en Hungría probablemente no pasará a la historia por su dramatismo -en Hungria no hubo muertes como en Rumanía o en Lituania- ni tampoco por su impetuosidad - los húngaros no conseguirían detener la respiración del mundo como los polacos al imponerse en las urnas al Partido Comunista, o los checos al movilizarse masivamente en las calles de Praga-, pero es seguro que durante mucho tiempo quedará como ejemplo de qué sea una transición pacífica y ordenada - modélica, pues- desde el autoritarismo ha- 
cia la democracia. Una transición que ya se ha descrito, acertadamente, como «una revolución negociada».

La característica más señalada del proceso democratizador húngaro es su gradualismo. De hecho, es difícil fijar en un momento concreto la fecha de su arranque, toda vez que desde mediados de los sesenta el régimen de János Kádár se embarcaría en una política aperturista en lo económico desde la que, también gradualmente, se pasaría a un cierto aperturismo político. Este se manifestaría, si no en un reconocimiento del pluralismo político, sí en una ostensible relajación del control del EstadoPartido sobre los ciudadanos y en una franca suavización de su labor adoctrinadora, hechos ambos que empujarian a un buen número de estudiosos a rechazar su calificación como "totalitario" para preferir en su lugar términos como "paternalista" o " autoritario".

Aun así, no es infrecuente situar el origen de los definitivos procesos de cambio que conducirían a Hungría hasta la democracia en la suṣtitución de János Kádár por Karóly Grósz como Secretario General del MSzMP —el Partido Comunista húngaro-, verificada en la Conferencia Extraordinaria de mayo de 1988. Grósz, más liberal, no tardaría en rodearse de nuevos nombres, entre los que bien pronto destacarían los de Imre Poszgay como Secretario General del Frente Popular Patriótico, Miklós Németh como Presidente del Gobierno y Reszo Nyers como todopoderoso ministro de economía. Éstos, colocados en puestos relativamente alejados del aparato del Partido, pronto se labrarian un cierto apoyo popular, y con el tiempo acabarian presentándole batalla al propio Grósz. Este segundo momento clave se produciría en junio de 1989, al acordar el C.C. del MSzMP la sustitución de la Secretaría General por una dirección colegiada en la que se integrarian los cuatro líderes, bajo la presidencia de Nyers. El partido apostaba así por la liberalización, no sólo económica sino también política.

Sin embargo para entonces el margen de maniobra del MSzMP se hallaba ya considerablemente mermado. Si durante $1988-y$, naturalmente, en anteriores momentos- el Partido Comunista había sido el protagonista único de la vida politica húngara y el auténtico motor del cambio, durante los últimos meses habían comenzado a gestarse una larga serie de movimientos opositores que, para la primavera de 1989, se hallaban ya en condiciones de imponer su fuerza a un partido cada vez más debilitado, dividido y aislado. Así, no resultaría exagerado afirmar que en el momento de la subida al poder de Pozsgay, Németh y Nyers, al partido no le quedaba sino negociar el cómo y el cuándo de su relevo en el poder y buscar el modo de seguir ocupando un lugar significativo en el nuevo sistema político que se avecinaba. 
Los grupos de oposición, que para aquel entonces poseian ya un perfil muy similar al que un año más tarde presentarian de cara a las elecciones, se hallaban encabezados por el llamado Foro Democrático Húngaro (MDF). Fundado en septiembre de 1987 a raíz de una reunión de destacados intelectuales y artistas, el MDF se presentaría en sus orígenes como un simple foro de discusión y debate sin intereses directos en la lucha política y destinado a mediar entre el gobierno socialista y los grupos de oposición más radicales. Pero con el tiempo, el Foro iría acentuando cada vez más su presencia política, constituyéndose al final como partido de corte nacionalista y populista. La designación de Joszef Antall como líder del grupo llevaría a éste, no obstante, a una marcada aproximación a las tesis democristianas.

Frente al populismo del Foro Democrático, la Alianza de los Demócratas Libres (SzDSz) de János Kis, Péter Tölgyessy e Iván Peto, encarnaría en cierto modo la oposición más radical de la intelectualidad urbana y liberal. Formada fundamentalmente por intelectuales disidentes, defensores de los derechos humanos y jóvenes economistas de corte liberal vinculados con los sectores más vanguardistas del ejecutivo, la Alianza subrayaría en sus propuestas la necesidad de un cambio político radical y de una decidida entrada en el mundo de la economía libre.

Junto a estos dos grandes grupos, sería necesario mencionar, cuanto menos, a otros tres. De una parte, la Alianza de Jóvenes Demócratas (Fidesz), que se convertiría un caso único en el panorama político europeo al alcanzar casi un $10 \%$ de los votos sin haber dejado de ser en ningún momento una agrupación eminentemente juvenil -la edad media de sus 21 parlamentarios sería de 28 años-, merced a un programa de reformas radical y a una campaña electoral atrevida e imaginativa. De otra, el Partido Socialdemócrata, que intentaría rehacer su imagen de gran partido de la clase obrera en la Hungría de entreguerras, intentando apartar de la memoria del electorado su larga etapa de colaboracionismo con el comunismo después de su forzosa integración en el Frente Popular Patriótico. Por último, también el Partido Independiente de los Pequeños Propietarios (FKgP) intentaría revitalizar su antiguo potencial -habia sido, con un $54 \%$ de los votos, el gran vencedor de las últimas elecciones democráticas de la Hungría precomunista - apelando a la necesidad de devolver las tierras confiscadas por el Estado comunista a sus legítimos propietarios.

Por su parte, el MSzMP continuaría durante todo el año 1989 sumido en el debate entre conservadores y reformistas. Con el tiempo, serian éstos últimos quienes se harían con el control del partido, el cual, tras su congreso de octubre de ese año, acordaría transformarse en un partido de corte socialdemócrata bajo la nueva denominación de Partido 
Socialista Húngaro (MSzP). Ello provocaría una estimable escisión a su izquierda, toda vez que un buen número de sectores conservadores del partido optarían por el mantenimiento de la denominación y de la ortodoxia del primer momento. La decisión del Parlamento de disolver las milicias obreras y de impedir la presencia del partido en los puestos de trabajo, así como el estrecho control al que sería sometida su financiación, mermarian notablemente su capacidad operativa y lo colocarian de cara a los comicios en una situación prácticamante equiparable a la del resto de las fuerzas concurrentes.

La planificación de las elecciones sería fruto, como había ocurrido en Polonia y ocurriría después en los demás países de la zona, de una larga serie de negociaciones entre el gobierno y la oposición. Éstas darían comienzo en el verano de 1989, y para septiembre se hallarían ya ultimados los proyectos de Ley Electoral, de Ley de Partidos y de Reforma Constitucional. Todos ellos serían aprobados sin apenas crítica ni oposición por un Parlamento de mayoría comunista que hacía tiempo había dejado de ser el verdadero centro de decisión del país.

La Ley Electoral de 20 de octubre de 1989 introduciría en Hungría un sistema electoral inédito y extremadamente complejo, digno - como alguien diría- del país que vio nacer al inventor del famoso Cubo de Rubik. Así, 176 escaños - de los 386 que componían la Országgyulés- debían ser elegidos en circunscripciones uninominales por el sistema de mayoría absoluta a dos vueltas. Otros 152 habían de serlo de forma proporcional mediante listas presentadas por los partidos en las 20 circunscripciones electorales (los 19 condados, más Budapest) del país. Y por último, los restantes 58 escaños se repartirían proporcionalmente entre las "listas nacionales" de los distintos partidos, sobre la base de los votos que cada uno había obtenido en los otros dos escrutinios pero que no habían servido entonces para la obtención de escaño. Naturalmente, cada elector disponía de dos votos - uno para el escrutinio mayoritario y otro para el proporcional-, y mientras que los escaños distribuidos proporcionalmente lo eran en la primera vuelta, los de la lista nacional lo eran después de la segunda y los de los distritos uninominales entre la una y la otra. Para acabar de complicar el modelo, la Ley Electoral establecía importantes trabas a la hora de presentar las candidaturas y de repartir los escaños. Así, para presentar una lista nacional era preciso haber concurrido a las elecciones en al menos siete circunscripciones territoriales, y para concurrir en una de éstas era necesario haberlo hecho antes en al menos una cuarta parte de los distritos uninominales del condado, en los que a su vez se precisaban 750 firmas para concurrir como candidato. Además, para la obtención de escaño, tanto en las listas territoriales como en la lista nacional, la Ley exigía haber obtenido al menos el $4 \%$ de los votos emitidos a nivel nacional. Todo ello generaría a la postre una 
forzada simplificación del mapa político húngaro, al reducirse a sólo seis el número de fuerzas con significativa presencia en la Cámara legislativa.

El sistema electoral resultaba ser así un sistema mixto, con elementos proporcionales y elementos mayoritarios, que a la vez concedía protagonismo a los partidos y a los candidatos individuales que éstos presentasen.

La campaña electoral previa a las elecciones resultaría en términos generales limpia, si bien no conseguiría despertar demasiado entusiasmo entre los electores húngaros. De los 54 partidos registrados en el momento de la convocatoria, sólo 28 llegarían a concurrir efectivamente a las elecciones, siendo sólo 19 los que presentasen al menos una lista regional y nada más que 12 los que, presentando al menos siete listas regionales, tendrian derecho a la presentación de lista nacional. La radio y la TV públicas, controladas por una comisión interpartidista, asegurarían con notable ecuanimidad una completa cobertura del proceso. En su transcurso, la mayor parte de las fuerzas concurrentes harían especial hincapié en la crítica al viejo sistema de partido único, descalificando en todo momento la opción socialista del MSzP. Paralelamente, el conflicto entre los dos principales partidos de la oposición no tardaría demasiado en aflorar, produciéndose un cruce de acusaciones de cierta virulencia: para el Foro, el acentuado liberalismo de la Alianza parecía camuflar una evidente falta de patriotismo, mientras que para la Alianza el populismo del Foro escondia en realidad un nacionalismo exacerbado lindante con el antisemitismo.

Los resultados electorales de la primera vuelta (véase cuadro VI) no resultarían muy distintos de los previstos. EI Foro Democrático y la Alianza de los Demócratas Libres - los grandes favoritos- obtendrían desde el primer momento una sustanciosa ventaja sobre sus más directos rivales, que, por este orden y a notable distancia, serían los Pequeños Propietarios, el Partido Socialista Húngaro, Fidesz y los cristianodemócratas. La sorpresa vendría de la mano de los socialdemócratas y de los comunistas ortodoxos, que, ligeramente por debajo de la barrera del $4 \%$, quedarían apartados por completo del reparto de escaños. Por contra, los cristianodemócratas del KDNP obtendrían en los distritos rurales del norte del país resultados bastante por encima de los esperados.

Para la segunda vuelta quedarían pendientes de repartir prácticamente todos los escaños que debían disputarse por el principio mayoritario, toda vez que sólo en cinco circunscripciones había conseguido un candidato la requerida mayoría absoluta. Según la Ley Electoral, a esta segunda vuelta debían concurrir los tres candidatos que en la primera hubiesen obtenido el mayor número de votos, más todos aquellos que hu- 


\section{Cuadro VI \\ HUNGRÍA \\ Elecciones parlamentarias}

1. ${ }^{a}$ vuelta: 25 de marzo de 1990. 2. ${ }^{a}$ vuelta: 8 de abril de 1990.

Participación: 1. ${ }^{a}$ vuelta: 5.093 .119 electores (63,1\%). 2. ${ }^{a}$ vuelta: 3.543 .841 electores $(45,5 \%)$

Asamblea Nacional (Országgyulés): 386 escaños

\begin{tabular}{|c|c|c|c|c|c|c|c|c|}
\hline & $\begin{array}{c}\text { N. votos } \\
1 .{ }^{a} \text { vuelta } \\
\text { (listas territ.) }\end{array}$ & $\begin{array}{l}\% \text { votos } \\
1 .^{a} \text { vuelta }\end{array}$ & $\begin{array}{c}\% \text { votos } \\
2 .{ }^{a} \text { vuelta }\end{array}$ & $\begin{array}{l}\text { Esc. C.U. } \\
1 .^{s} \text { vuelta }\end{array}$ & $\begin{array}{l}\text { Esc. C.U. } \\
2 .{ }^{ \pm} \text {vuelta }\end{array}$ & $\begin{array}{c}\text { Esc. List. } \\
\text { territ. }\end{array}$ & $\begin{array}{l}\text { Esc. List. } \\
\text { nacional }\end{array}$ & $\begin{array}{l}\text { Escaños } \\
\text { totales }\end{array}$ \\
\hline MDF (Foro Democrático Húngaro) .......................... & 1.214 .328 & 24,73 & 41,22 & 3 & 112 & 40 & 10 & 165 \\
\hline $\begin{array}{l}\text { SzDSz (Alianza de los Demócratas Libres) ........ } \\
\text { FKgP (Partido Independiente de los Pequeños }\end{array}$ & 1.050 .735 & 21,39 & 29,69 & 0 & 34 & 34 & 23 & 91 \\
\hline Propietarios) & 576.305 & 11,73 & 10,64 & 0 & 11 & 16 & 23 & 44 \\
\hline MSzP (Partido Socialista Húngaro) ........................ & 531.246 & 10,89 & 6,18 & 0 & 1 & 14 & 18 & 33 \\
\hline Fidesz (Alianza de los Jóvenes Demócratas) .... & 436.726 & 8,95 & 2,15 & 0 & 1 & 8 & 12 & 21 \\
\hline KDNP (Partido Popular Cristiano Demócrata) ... & 281.670 & 6,46 & 3,69 & 0 & 3 & 8 & 10 & 21 \\
\hline MSzMP (Partido Socialista Obrero Húngaro).... & 180.956 & 3,68 & - & 0 & 0 & 0 & 0 & 0 \\
\hline MSzDP (Partido Socialdemócrata) .......................... & 174.419 & 3,55 & - & 0 & 0 & 0 & 0 & 0 \\
\hline ASz (Alianza Agraria) & 153.801 & 3,13 & - & 0 & 1 & 0 & 0 & 1 \\
\hline 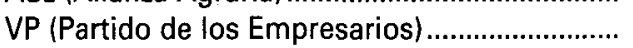 & 92.688 & 1,89 & - & 0 & 0 & 0 & 0 & 0 \\
\hline HVK (Coalición Electoral Patriótica) ....................... & 91.915 & 1,87 & - & 0 & 0 & 0 & 0 & 0 \\
\hline Candidatos apoyados por varios partidos.......... & - & - & 3,50 & 0 & 4 & 0 & 0 & 4 \\
\hline Independientes & - & - & 2,93 & 2 & 4 & 0 & 0 & 6 \\
\hline
\end{tabular}


biesen obtenido al menos el $15 \%$ de éstos. Sin embargo, cuando el porcentaje de participación hubiese sido inferior al $50 \%$, el paso a la segunda vuelta quedaba garantizado para todos los contendientes. En base a ello, lograrían el pase a la segunda vuelta 154 candidatos del Foro, 135 de la Alianza, 69 del FKgP, 58 del MSzP, 21 del KDNP y sólo 12 de Fidesz. Como es natural, los partidos desplegarían en el entretanto intensas negociaciones de cara a asegurarse apoyos mutuos. Ello no daría lugar en términos generales a pactos formales, pero sí que propiciaría numerosas colaboraciones, de una parte entre los Demócratas Libres y Fidesz y de otra entre el Foro y los Cristianodemócratas, manteniendo los Pequeños Propietarios una actitud un tanto más voluble.

El resultado de la segunda vuelta supondría una victoria rotunda para el MDF. Éste no sólo se haría con las 80 circunscripciones en las que había quedado vencedor en la primera vuelta, sino que elevaría el número de sus victorias a 111, habiendo de sumarles a éstas las tres logradas en la primera ronda. La SzDSz, totalmente rebasada, no conseguiría más que 35 escaños, a pesar de haber quedado en primer lugar dos semanas antes en 63 circunscripciones. Del resto de los partidos, tan sólo los $\mathrm{Pe}$ queños Propietarios lograrían mantener sus posiciones, logrando un total de 11 escaños, tantos como primeros puestos habian conseguido en la primera vuelta.

Por su parte, el reparto de los escaños de la lista nacional serviría en cierto modo -ésa era su finalidad- para equilibrar el reparto de escaños resultante de los otros dos modelos de escrutinio. Así, el Foro obtendría finalmente en torno al $42 \%$ de los escaños, la Alianza un $23 \%$, los Pequeños Propietarios un $11 \%$, los Socialistas un $8 \%$ y, finalmente, Cristianodemócratas y Jóvenes Demócratas un 5\% cada uno.

Un balance global de las elecciones obligaría a calificar al MDF como un auténtico catch-all-party. Sus resultados se revelarían como enormemente equilibrados a todo lo largo y ancho del país, recogiendo asimismo un apoyo muy similar en los diferentes estratos sociales y en los distintos grupos de edad. Además, el MDF se revelaría como especialmente hábil a la hora de arrancar votos que antes habían sido otorgados a otras organizaciones, como lo demostrarían sus sorprendentes resultados de la segunda vuelta.

Por su parte, tanto la Alianza como los Jóvenes Demócratas obtendrían sus mejores resultados entre los sectores más jóvenes, más educados y más urbanos. Su principal bastión lo constituiría la capital, Budapest, en donde la SzDSz lograría un $27,1 \%$ de los votos... por más que perdiese a manos del Foro la mayor parte de los escaños en juego. Los Pequeños Propietarios se defenderían mejor en los distritos rurales 
del Sur y entre los sectores poblacionales de más edad y menor nivel cultural, al tiempo que los Cristianodemócratas, apoyados en un electorado prácticamente idéntico, se centrarían en la mitad norte del país. En última instancia, los socialistas obtendrían sus mejores porcentajes en la capital, así como en los distritos mayormente industriales, si bien su concurrencia en las diferentes circunscripciones uninominales acabaría saldándose con una derrota lindante con el ridículo: sólo Mátyás Szuros -a la sazón presidente de la República- lograría imponerse en su distrito, al tiempo que Pozsgay sería derrotado por un candidato de Fidesz y Németh se vería obligado a concurrir como independiente para asegurar su escaño.

Constituidas las Cámaras, la formación de un nuevo gobierno sería confiada al líder del Foro Democrático Húngaro, Jószef Antall, el cual contaría para ello con el apoyo de las dos fuerzas más próximas al Foro, los Cristianodemócratas y los Pequeños Propietarios. Llegado el momento de elegir al nuevo Presidente de la República, un pacto postelectoral entre el MDF y la SzDSz permitiría investir para este cargo a Árpád Göncz, un destacado intelectual y disidente próximo a la Alianza. De este modo tan sólo los ex-comunistas quedaban ostensiblemente fuera del diálogo gobierno-oposición.

Todo este panorama daría sin embargo un vuelco radical apenas unos meses después. En concreto, las elecciones municipales de octubre de 1990 supondrían para la coalición gubernamental un muy serio revés, al tiempo que supondrían un importante éxito para la oposición liberal encarnada por Fidesz y el SzDSz.

El sistema electoral utilizado prevería, al modo polaco, dos modos de escrutinio distintos. Para las 2.930 poblaciones de menos de 10.000 habitantes, comprensivas de un tercio aproximadamente del cuerpo electoral, el escrutinio sería de tipo mayoritario, eligiéndose de forma separada los concejales y el alcalde. Para las 162 ciudades que superaban esa cifra, y que comprendían los otros dos tercios del censo, se optaría por combinar el mencionado sistema mayoritario con el proporcional y de lista, quedandó la elección del alcalde en manos de los concejales electos. Por último, en Budapest se procedería a la elección a un mismo tiempo de una corporación municipal de 66 miembros y de 22 consejos de barrio, corriendo la elección de alcalde de cargo tanto de aquélla como de los representantes de éstos. Estas particularidades, unidas a las profundas diferencias sociológicas entre la Hungría rural y la urbana, forzarian resultados fuertemente divergentes en uno y otro contexto. Así (véase cuadro VII), en los distritos rurales nada menos que el $83 \%$ de las alcaldías iría a parar a manos de candidatos independientes, lo que sin ninguna duda ponía en evidencia la superficial implantación en la Hungría 


\section{Cuadro VII \\ HUNGRÍA \\ Elecciones municipales}

1. ${ }^{a}$ vuelta: 30 de septiembre de 1990. 2. ${ }^{a}$ vuelta: 14 de octubre de 1990. Participación en poblaciones de menos de $10.000 \mathrm{h.:}$

1. ${ }^{a}$ vuelta: $50,9 \%$. 2. ${ }^{\mathrm{a}}$ vuelta: $33,8 \%$

Participación en poblaciones de más de 10.000 h.:

1. ${ }^{\text {a }}$ vuelta: $33,0 \%$. 2. ${ }^{\text {a }}$ vuelta: $28,6 \%$

\begin{tabular}{|c|c|c|c|}
\hline$\%$ de Concejales electos & $\begin{array}{c}\text { En núcleos } \\
\text { rurales }\end{array}$ & $\begin{array}{c}\text { En núcleos } \\
\text { urbanos }\end{array}$ & $\begin{array}{c}\text { En } \\
\text { Budapest }\end{array}$ \\
\hline SzDSz (Alianza de los Demócratas Libres) ............. & 3,95 & 23,43 & 37,8 \\
\hline MDF (Foro Democrático Húngaro) ............................ & 4,35 & 20,83 & 30,3 \\
\hline Fidesz (Alianza de los Jóvenes Demócratas) ........ & 0,64 & 18,01 & 19,7 \\
\hline MSzP (Partido Socialista Húngaro) ............................. & 1,12 & 10,41 & 7,5 \\
\hline KDNP (Partido Popular Cristiano Demócrata) ........ & 2,77 & 10,28 & 4,5 \\
\hline FKgP (Partido Ind. de los Pequeños Propietarios) & 6,23 & 9,43 & 0 \\
\hline MSzMP (Partido Socialista Obrero Húngaro) ......... & 0,21 & 1,28 & 0 \\
\hline 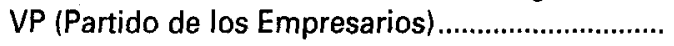 & 0,42 & 0,85 & 0 \\
\hline ASz (AlianzaAgraria) & 1,33 & 0,65 & 0 \\
\hline 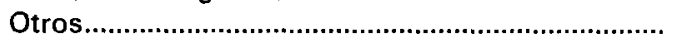 & 7,76 & 4,83 & 0 \\
\hline Independientes & 71,19 & - & 0 \\
\hline
\end{tabular}

rural de la práctica totalidad de las fuerzas políticas existentes. De éstas, sólo el Partido de los Pequeños Propietarios lograría en este su terreno más propicio unos resultados apreciables, haciéndose con el $3,7 \%$ de las alcaldías y el $6,2 \%$ de los consejeros municipales. De los alcaldes así elegidos, un porcentaje apreciable resultaría haber desempeñado el mismo puesto durante el régimen comunista, dato que llevaría a más de uno a apuntar - sin que ello parezca en verdad fundado - un eventual resurgimiento del socialismo más ortodoxo.

Por lo que respecta a los grandes núcleos urbanos, lo más llamativo sería, en un principio, el ínfimo porcentaje de participación cosechado tanto en la primera como en la segunda vuelta. Habida cuenta de que la Ley Electoral Municipal exigía al menos un $40 \%$ de participación para dar por válida la elección verificada en la primera vuelta, más de un $90 \%$ de los municipios en cuestión se verían forzados a acudir de nuevo a las urnas el 14 de octubre. Los resultados finales supondrían una sonada derrota para la coalición gubernamental: mientras que el MDF perdía nada menos que seis puntos respecto de sus resultados en las elecciones ge- 
nerales, el FKgP perdía casi cuatro, salvándose del naufragio tan sólo los democristianos del KDNP, que conseguían una interesante mejoría en sus resultados. La Alianza de los Demócratas Libres, por su parte, tendría que conformarse con mantener su cuota de voto, pero a falta de más serios competidores acabaría consiguiendo la importantísima alcaldía de Budapest para su candidato Gábor Demszky. Los grandes triunfadores de la jornada serían sin duda los jóvenes de Fidesz, que mejorarían ostensiblemente sus resultados de la primavera anterior y conseguirían quedar en tercer lugar en el cómputo final de votos, a escasa distancia del Foro Democrático. En términos generales los liberales conseguirían vencer en casi todas las grandes ciudades, mientras que en los pequeños núcleos de población los mejores resultados serían para las candidaturas independientes, logrando también los socialistas reformados del MSzP unos excelentes resultados.

Todo ello supondría una importante inyección de inestabilidad sobre el ya inestable panorama político húngaro, en el que, si bien no se han llegado a registrar hasta el momento enfrentamientos de relevancia, sí es claramente perceptible un creciente descontento ante la lentitud de la transición y la poca entidad de sus logros. El enorme porcentaje de abstención verificado en las elecciones municipales y el enorme número de sufragios en favor de las pequeñas candidaturas locales constituye, seguramente, el mejor testimonio de tal situación y el más importante objeto de reflexión para la nueva clase política húngara.

\section{POLONIA: LA PAULATINA DEMOCRATIZACIÓN}

Las elecciones parlamentarias polacas de la primavera de 1989 fueron sin duda un hito decisivo en el proceso de desmoronamiento de los regímenes comunistas en el este de Europa. Convocadas en un ambiente poco propicio para la oposición, en un momento histórico en el que poner en duda el status quo salido de Yalta no era sino una fantasía y al amparo de una ley electoral que hacía por principio imposible una victoria de las candidaturas anticomunistas, supusieron sin embargo un éxito sin precedentes para el sindicato Solidaridad, que en pocos meses pasaría de la clandestinidad a la presidencia del gobierno.

Pero, con todo, esa rotunda victoria electoral de Solidaridad no trajo consigo -en modo alguno podía hacerlo- la automática disolución del sistema político de la Polonia comunista. En primer lugar, no lo olvidemos, porque la victoria de Solidaridad era una victoria moral de difícil 
traslación a la práctica: aunque las candidaturas apoyadas por el sindicato católico obtendrían en torno a un $70 \%$ del total de votos emitidos, las previsiones de la Ley Electoral de 7 de abril de 1989 le permitían al Partido Comunista retener en sus manos un $38 \%$ de los escaños de la Cámara Baja y otorgaban a sus aliados otro $28 \%$. Incluso en la hipótesis de que Solidaridad arrasase en los comicios - como así ocurrió-, su presencia en las Cámaras habría de compatibilizarse con la de una mayoría de parlamentarios comunistas o pro-comunistas. Pero, paralelamente, porque la renovación del Parlamento dejaba de momento intacto uno de los centros claves del poder del Estado - los entes locales-, al tiempo que permitía un escasísimo margen de maniobra de cara a la renovación de otro de esos centros: la recién creada Presidencia de la República. En cierto modo podría decirse que la vida política polaca durante 1990 se encaminaría a solventar estas dos últimas antinomias, bajo los condicionantes impuestos por la primera.

En efecto: una de las primeras dificultades con las que se encontraría el gobierno de Tadeusz Mazowiecki desde el momento de su toma de posesión, en el verano de 1989, sería la que suponía la presencia en los órganos de gobierno locales de numerosos miembros de la nomenklatura del partido, poco proclives a secundar la imprescindible democratización de la vida política polaca. Sin embargo, la elaboración de una nueva Ley sobre la Autonomía Local y de una Ley Electoral Municipal demoraría considerablemente la necesaria renovación de estos órganos, que no tendría lugar hasta finales de mayo de 1990.

La Ley Electoral Municipal de 8 de marzo de 1990 preveía sistemas electorales diferentes para los municipios grandes y para los más pequeños. En los municipios de más de $\mathbf{4 0 . 0 0 0 ~ h a b i t a n t e s ~ l a s ~ e l e c c i o n e s ~ s e ~ v e - ~}$ rificarian por un sistema proporcional y de lista con voto preferencial, mientras que los municipios de menos de 40.000 habitantes se verían divididos en distritos uninominales en los que operaría el principio mayoritario a una sola vuelta. La presentación de candidaturas era enteramente libre, no precisándose más que un insignificante número de firmas. Es por ello que bien puede afirmarse que las presentes fueron a la vez las primeras elecciones enteramente libres celebradas en Polonia desde el fin de la II Guerra Mundial y las primeras de ámbito local en toda la Europa del Este.

La nómina de los contendientes presentaría, respecto de los que protagonizaron las elecciones de 1989, cambios parciales. Así, mientras que Solidaridad movilizaría a sus Comités Cívicos de forma similar a lo que lo había hecho con ocasión de las elecciones parlamentarias, el antiguo Partido Comunista acudiría a la contienda bajo unas nuevas siglas - Socialdemocracia de la República Polaca- y una nueva ideología, fru- 
to de su congreso de enero. Junto con él, acudirían también a la convocatoria electoral los partidos Campesino y Demócrata - antiguos aliados del Comunista-, así como unos 80 partidos menores y varios cientos de candidaturas independientes de carácter puramente local.

Las elecciones, celebradas en un ambiente escasamente entusiasta, arrojarían un nivel de participación un tanto desalentador. Los resultados (véase cuadro VIII) diferirian sensiblemente según el carácter de los municipios. En aquellos elegidos por el sistema de listas, la victoria de los Comités Cívicos de Solidaridad sería arrolladora, convirtiendo en insignificante la presencia del resto de las fuerzas. En cambio, en los municipios menores, la menor politización de los comicios y la propia dinámica del sistema electoral uninominal potenciaria la aparición con éxito de una multiplicidad de candidaturas independientes que a la postre obtendrían más del $40 \%$ de los escaños en juego. Solidaridad se tendría que conformar así con una cifra ligeramente inferior, consiguiendo el Partido Campesino un nada despreciable porcentaje por encima del 6\%. Se repetía, pues, la arrolladora victoria de Solidaridad, que, sin las trabas procedimentales de 1989, se convertía en la fuerza hegemónica del panorama municipal polaco.

Tal situación daría un vuelco significativo durante los meses inmediatamente posteriores a la consulta electoral. Solidaridad había conseguido aglutinar a la práctica totalidad de los sectores opositores polacos mientras el objetivo perseguido había sido la quiebra del sistema comunista. Pero una vez lograda la ruptura, las vías hacía la normalización democrática resultarían ser demasiadas y demasiado distintas como para mantener la cohesión en un grupo en el que, por lo demás, habian hallado cobijo las tres cuartas partes de la sociedad polaca. El propio Lech Walesa abogaría el 20 de junio, desde las páginas de Gazeta Wyborcza, porque en Solidaridad se asumiese el hecho de la existencia de muy distintas sensibilidades políticas dentro del movimiento sindical, y porque éstas se manifestasen lo antes posible y con claridad, so pena de que el sindicato acabase convirtiéndose en un nuevo Frente Popular destructor de todo pluralismo. La ruptura se materializaría bien pronto. De un lado, las tesis más populistas de Walesa —reelegido en abril presidente del sindicato- se encarnarían en la llamada Coordinadora del Centro, dirigida por los hermanos Kaczynski y bien próxima ideológica y personalmente al Primado Glemp. De otro, las posturas más liberales del Gobierno de Mazowiecki hallarían respaldo político en el grupo Movimiento Ciudadano-Acción Democrática (ROAD), encabezado, entre otros, por Zbigniew Bujak, Zofia Kuratowska, Jacek Wozniakowski y Jerzy Turowicz. Entre unos y otros comenzaría así un intercambio de acusaciones de notables proporciones. Si para la Coordinadora del Centro, el Gobierno Mazowiecki parecía ignorar el progresivo descenso del nivel de vida de los 


\section{Cuadro VIII \\ POLONIA \\ Elecciones locales \\ 27 de mayo de 1990 \\ Participación: $42 \%$}

\begin{tabular}{|c|c|c|}
\hline$\%$ de escaños obtenidos & $\begin{array}{c}\text { En poblaciones } \\
\text { de menos } \\
\text { de } 40.000 \\
\text { habitantes }\end{array}$ & $\begin{array}{c}\text { En poblaciones } \\
\text { de más } \\
\text { de } 40.000 \\
\text { habitantes }\end{array}$ \\
\hline KO S (Comités cívicos de Solidaridad) ........................ & 38,22 & 74,03 \\
\hline NZSS S (Sindicato Obrero Solidaridad) ..................... & 1,20 & 3,95 \\
\hline SD (Partido Demócrata) & 0,45 & 1,83 \\
\hline SdRP (Socialdemocracia Polaca, antes PZPR) .......... & 0,14 & 1,03 \\
\hline PSL (Partido Campesino Polaco, antes ZSL) ............. & 6,26 & 0,73 \\
\hline 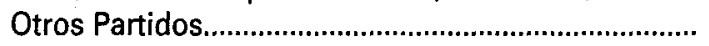 & 10,53 & 16,26 \\
\hline Candidaturas independientes & 43,20 & 2,14 \\
\hline
\end{tabular}

obreros, al tiempo que se mostraba indiferente ante la pervivencia de restos del antiguo sistema comunista, para los partidarios del Primer Ministro, Walesa estaba pecando de irresponsabilidad en sus propuestas, cayendo en un populismo demagógico y postulando un integrismo en lo religioso poco compatible con el proceso democratizador en curso.

Así las cosas, el 18 de septiembre se produciría el anuncio de que el General Jaruzelski, Presidente de la República desde su elección por el Parlamento en julio de 1989, estaría dispuesto a abandonar el puesto, dando paso así a unas elecciones presidenciales anticipadas de cuya necesidad casi nadie dudaba. Habida cuenta de que Walesa había anunciado desde hacia tiempo su intención de concurrir a tales elecciones, la duda a despejar era la de cuál sería el candidato del ala más liberal de Solidaridad, y más en concreto si Mazowiecki aceptaría ser su contrincante. La proclamación en ese sentido no se haría esperar demasiado, y, finalizado el plazo para la inscrición de las candidaturas, resultarían ser cinco los contendientes.

La campaña, planteada en un principio como un enfrentamiento entre Walesa y Mazowiecki, cambiaría de cariz con el paso de los dias, a medida que se fuesen afianzando en los sondeos las posibilidades de un desconocido hombre de negocios canadiense de origen polaco llamado Stanislaw Tyminski. Las propuestas de Tyminski, enormemente elementales y demagógicas, parecían poder resumirse en su idea de llevar a Po- 


\begin{tabular}{|c|c|c|c|c|}
\hline \multicolumn{5}{|c|}{$\begin{array}{c}\text { Cuadro IX } \\
\text { POLONIA } \\
\text { Elecciones presidenciales } \\
1 .{ }^{a} \text { vuelta: } 25 \text { de noviembre de } 1990 . \\
2 .^{a} \text { vuelta: } 9 \text { de diciembre de } 1990 \\
\text { Participación: } 1 .^{a} \text { vuelta: } 16.702 \text { electores }(60,63 \%) \\
\text { 2. }{ }^{a} \text { vuelta: } 14.650 .037 \text { electores }(53,40 \%)\end{array}$} \\
\hline & \multicolumn{2}{|c|}{ 1. vuelta } & \multicolumn{2}{|c|}{$2 .^{a}$ vuelta } \\
\hline & $N .{ }^{\circ}$ votos & $\%$ & $N .^{\circ}$ votos & $\%$ \\
\hline (Coordinadora del Centro) .......... & 6.569 .889 & 39,96 & 10.622 .696 & 74,2 \\
\hline minski (Independiente) ................ & 3.797 .605 & 23,10 & 3.683 .098 & 25,7 \\
\hline owiecki (Mov. de Acción Dem.). & 2.973 .264 & 18,08 & - & - \\
\hline Cimiosewicz (SdRP) ..................... & 1.514 .025 & 9,21 & - & - \\
\hline 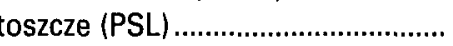 & 1.176 .175 & 7,15 & - & 一 \\
\hline zulski (nacionalista católico) .......... & & 2,50 & - & - \\
\hline
\end{tabular}

Ionia a una economía plenamente capitalista, sin trauma alguno para sus estructuras sociales, y en su afirmación de que durante su mandato pondría al alcance de todos los polacos unas posibilidades de enriquecimiento similares a las que él había disfrutado en el extranjero. Tales propuestas, unidas a un estudiado apoliticismo, causarían un fuerte impacto en un electorado decepcionado por las crecientes estrecheces que había traído consigo el proceso democratizador y cansado de la continua disputa entre los distintos sectores de Solidaridad, de modo que, celebrada la primera vuelta electoral, Tyminski se alzaría (ver cuadro IX) con un inesperado $23 \%$ de los votos, desplazando a Tadeusz Mazowiecki hasta la tercera posición y pasando con Walesa a la segunda vuelta. Por sectores de población, Walesa resultaría el gran triunfador en las grandes ciudades - con un $48 \%$ de los votos en Varsovia, un $51 \%$ en Cracovia y hasta un $56 \%$ en su ciudad de Gdansk-, pese a que su apoyo más bajo lo lograría entre los white collars. Tyminski se defendería bien entre los jóvenes, captando significativos porcentajes entre los obreros industriales. Por su parte, Mazowiecki se revelaría extremadamente endeble ante estos últimos, recogiendo porcentajes mínimos entre el campesinado.

El éxito inesperado de Tyminski alteraría radicalmente las previsiones para la segunda vuelta. Prevista inicialmente como un mano a mano entre los dos líderes de Solidaridad -el resto de los candidatos no parecían tener, a priori, posibilidad alguna-, se convirtió finalmente en una carrera por parar al desconocido Tyminski, respecto del cual no ce- 
sarian de publicarse sorprendentes revelaciones. Ello forzaría un reagrupamiento de fuerzas en torno a Walesa, que se concretaría en la recomendación hecha pública el $\mathbf{3 0}$ de septiembre por la jerarquía católica polaca en favor de su candidatura y en el apoyo que el Primer Ministro Mazowiecki le brindaría pocos días después. Así las cosas, la segunda vuelta se convertiría en un triunfo absoluto de Walesa, que, con una participación sensiblemente menor, obtendría cuatro millones de sufragios más, triplicando así los de su contrincante. Tal triunfo sólo puede ser explicado merced a una transferencia de voto de grandes dimensiones desde todas las candidaturas no comunistas - y no sólo desde la de Mazowiecki- hacia la de Walesa, que de este modo conseguiría subir sorprendentemente, mucho más sin duda que si el candidato superviviente hubiese sido el Primer Ministro. No faltaría quien dijese, con cierta sorna, que el fenómeno Tyminski habia obligado a todos los polacos sensatos a dar su voto a Walesa, cosa que de ninguna otra forma hubiese podido ocurrir.

La investidura de Lech Walesa como Presidente de la República de Polonia el 22 de diciembre de 1990 estaría cargada de simbolismo. El viejo líder sindical recibiría las insignias presidenciales de manos del último presidente de la Polonia pre-comunista, en ausencia del General Jaruzelski y ante la enseña nacional que ondeaba en el Palacio Real de Varsovia en el momento de la invasión alemana de 1939, marcando así bien claramente las intenciones de su mandato: hacer de los últimos cincuenta años de la historia de Polonia un paréntesis felizmente cerrado de la historia y emprender el camino del futuro sin ninguna de sus lacras.

\section{RUMANÍA: ¿UNA REVOLUCIÓN TRAICIONADA?}

El proceso democratizador rumano viene condicionado por dos hechos clave que marcarán indeleblemente su rumbo y su ritmo. Nos referimos, de un lado, al carácter cruento que diferenciaría la Revolución rumana de todas las que la circundarían y, de otra, a la descorazonadora falta de tradiciones democráticas y de precedentes opositores de entidad en el momento de la caída del dictador Ceausescu.

La monarquía rumana de entreguerras, sólo aparentemente democrática, había dejado paso tras la II Guerra Mundial a un régimen comunista que, desde el ascenso al poder de los Ceausescu a mediados de los sesenta, había ido acentuando progresivamente sus rasgos más personalistas, aislacionistas y represores. Ello había impedido la existencia 
de una oposición mínimamente organizada y, más aún, incluso la existencia de una sociedad civil informada y crítica capaz de vertebrar, llegado el momento, un movimiento opositor cohesionado. De ahí que, llegado el momento de la ruptura, sólo los disidentes del propio partido se hallarían en condiciones de dotar de continuidad a las instituciones del Estado. Ello se verificaría por medio del llamado Frente de Salvación Nacional, movimiento de orígenes aún inciertos en el que acabarían integrándose la mayor parte de los protagonistas de los sucesos de la Navidad de 1989.

EI FSN aparecería en los primeros dias de la Revolución como un movimiento amplio destinado a cobijar en su seno a todos los opositores al régimen que habían colaborado en su caída y su gobierno se presentaría como una especie de gobierno de unidad nacional dirigido únicamente a evitar el vacio de poder en tanto eran preparados los instrumentos necesarios para operar una transición ordenada hacia el pluralismo. Pero su anuncio, el 23 de enero de.1990, de que concurriría como tal a las inminentes elecciones, unido a la presencia cada vez menos disimulable entre sus dirigentes de un elevado número de cuadros intermedios del antiguo Partido Comunista, haría pensar a muchos que la Revolución había sido traicionada... o más bien que la Revolución no había pasado de ser un ajuste de cuentas entre los distintos sectores del PCR, que ahora, bajo otras siglas, seguía detentando el poder. Tal interpretación, aun sin ser en modo alguno desdeñable, no era, sin embargo, la única posible. Para muchos, la aparición y el posterior desenvolvimiento del FSN son perfectamente lógicos si tenemos en cuenta que nos hallábamos ante una sociedad mayoritariamente educada en el conformismo ante el poder instituido, en la que, por lo demás, el hecho de que grandes masas de población se hubiesen visto empujadas a colaborar con la dictadura hacía impensable la aceptación social de un revanchismo generalizado. El socialismo reformista del FSN representaría así para muchos rumanos el modo más conveniente para avanzar en la imprescindible democratización, sin por ello hacer tabla rasa del pasado ni entrar irreflexivamente en un mundo capitalista que a muchos ciertamente asustaba.

Pero, además, el insoslayable protagonismo del FSN vendría también propiciado por el extremado fraccionamiento de los demás grupos de oposición: nada menos que 37 partidos entrarían en el Consejo de Unidad Nacional -especie de Parlamento provisional ideado por el Frente a comienzos de febrero del $90-$, situándose por encima de 80 el número de partidos que finalmente concurririan a las elecciones. De ellos sólo tres, la Unión Democrática Húngara de Rumanía (UDMR) y los partidos Nacional Liberal (PNL) y Nacional Campesino Cristianodemócrata (PNTcd), alcanzarían tras las elecciones una presencia significativa. El pri- 
mero representaba, obviamente, a la importante minoría húngara de Rumanía, la cual, situada fundamentalmente en la región de Transilvania, había supuesto durante la dictadura un permanente contratiempo para las políticas uniformizadoras de Bucarest. EI PNL, liderado por Radu Campeanu, pretendía ser el heredero del partido que con el mismo nombre había aglutinado en el período de entreguerras a la pujante burguesía urbana, reseñando en la actualidad con vehemencia la necesidad imperiosa de acelerar el retorno a las estructuras del mercado libre. Por su parte, el PNTcd, liderado por lon Ratiu, se dirigiría fundamentalmente al electorado rural - había sido el partido de los grandes terratenientes antes del advenimiento del comunismo-, haciendo especial hincapié en la defensa de la autonomía local y el la reestructuración de la agricultura. Sin embargo, el hecho de que ambas fuerzas viniesen lideradas por personas recién llegadas del exilio y que las dos resaltasen en su propaganda y mediante sus cuadros dirigentes su relación con las correspondientes formaciones precomunistas, hacía poco creíbles sus propuestas para la reconstrucción de un país cuyos problemas nada tenían que ver con los de la Rumanía de los años cuarenta. Su fracaso, así como el del Partido Socialdemócrata de $\mathrm{Cu}$ nescu y Dimitriu, debe interpretarse como el fruto más claro de su incapacidad para adaptar sus formulaciones y su liderago a los nuevos tiempos. Al margen de las mencionadas fuerzas, sólo el Partido Agrario Democrático, los grupos ecologistas PER y MER y la Alianza para la Unidad Rumana - brazo político del grupo ultranacionalista Vatra Romaneasca - obtendrían exiguas representaciones parlamentarias.

La Ley Electoral rumana prevería, tanto para el Senado como para la Asamblea de los Diputados, un sistema proporcional y de lista, sin barrera, sobre la base de los judete o condados, con reparto de restos a nivel nacional en el caso de la Asamblea y sin él en el del Senado. La fórmula, inicialmente lejana a la propuesta por el FSN, no dejaría de rendirle a esta formación magníficos frutos. $Y$ ello por tres órdenes de motivos. En primer lugar, porque le permitiría, cediendo en ello ante los partidos de la oposición, mantener con firmeza su propósito de convocar tempranamente las elecciones, haciendo valer así en toda su dimensión su ventaja organizativa inicial. En segundo lugar, porque de este modo conseguiría el Frente sacar de la mayor popularidad de sus líderes lliescu y Roman una ventaja que con un sistema mayoritario habría sido sin duda menor. $Y$, en último lugar, porque tratándose de un sistema sin barrera e incluso con reparto de restos a nivel nacional, el fraccionamiento de la oposición resultaba inevitable y su pérdida de operatividad enorme. La normativa aplicable contenía asimismo una cláusula que garantizaba la presencia en la Asamblea de un representante de cada una de las once minorias étnicas oficialmente registradas en el territorio rumano, así como disposiciones que privaban del sufragio pasivo a los que hubiesen cometido excesos bajo el régimen anterior, extremo este último que no lle- 


\section{Cuadro X \\ RUMANÍA \\ Elecciones parlamentarias y presidenciales \\ 20 de mayo de 1990 \\ Participación: 14.824 .912 electores (86\%) Adunarea Deputatilor (387 escaños)}

\begin{tabular}{|c|c|c|c|}
\hline & $N .^{o}$ votos & $\%$ votos & Escaños \\
\hline FSN (Frente de Salvación Nacional) ......................... & 9.089 .659 & 66,3 & 263 \\
\hline UDMR (Unión Demócrata Húngara de Rumanía).... & 991.601 & 7,2 & 29 \\
\hline 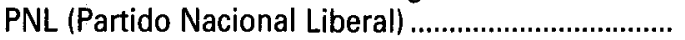 & 879.290 & 6,4 & 29 \\
\hline MER (Movimiento Ecologista Rumano) ................... & 358.864 & 2,6 & 12 \\
\hline PNTcd (Partido Nacional Campesino Crist. Dem.) .. & 351.357 & 2,6 & 12 \\
\hline AUR (Alianza para la Unidad Rumana) ...................... & 290.875 & 2,1 & 9 \\
\hline PDAR (Partido Agrario Democrático de Rumania).. & 250.403 & 1,8 & 9 \\
\hline 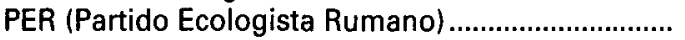 & 232.212 & 1,6 & 8 \\
\hline PSDR (Partido Socialista Dem. de Rumanía) ........... & 143.393 & 1,0 & 5 \\
\hline PSD (Partido Socialdemócrata Rumano).................... & 73.014 & 0,5 & 2 \\
\hline GDC (Grupo de Centro Democrático) ........................ & 65.941 & 0,4 & 2 \\
\hline Otros partidos & - & - & 7 \\
\hline Representantes designados por las minorías & & & \\
\hline nacionales & - & - & 9 \\
\hline
\end{tabular}

Senat (119 escaños)

\begin{tabular}{|c|c|c|c|}
\hline & N. ${ }^{\circ}$ votos & $\%$ votos & Escaños \\
\hline 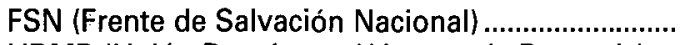 & 9.353 .006 & 67,0 & 92 \\
\hline UDMR (Unión Demócrata Húngara de Rumanía).... & 1.004 .353 & 7,2 & 12 \\
\hline PNL (Partido Nacional Liberal). & 985.094 & 7,0 & 9 \\
\hline MER (Movimiento Ecologista Rumano) .................... & 341.478 & 2,4 & 1 \\
\hline PNTcd (Partido Nacional Campesino Crist. Dem.) .. & 348.867 & 2,5 & 1 \\
\hline AUR (Alianza para la Unidad Rumana) ....................... & 300.473 & 2,1 & 2 \\
\hline PDAR (Partido Democrático Agrario de Rumanía).. & 221.720 & 1,5 & 0 \\
\hline 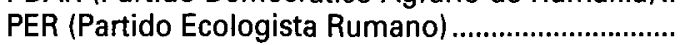 & 192.174 & 1,3 & 1 \\
\hline PSDR (Partido Socialista Democrático de Rumanía) & 152.989 & 1,1 & 0 \\
\hline PSD (Partido Socialdemócrata Rumano)................... & 67.762 & 0,5 & 0 \\
\hline GDC (Grupo de Centro Democrático) ......................... & 65.440 & 0,4 & 0 \\
\hline Independientes & - & - & 1 \\
\hline
\end{tabular}

Presidencia de la República

\begin{tabular}{|c|c|c|}
\hline & N. votos & $\%$ votos \\
\hline Ion Iliescu (Frente de Salvación Nacional)... & 12.232 .498 & 85,1 \\
\hline Radu Campeanu (Partido Nacional Liberal) .................................. & 1.529 .188 & 10,2 \\
\hline Ion Ratiu (Partido Nacional Campesino) ....................................... & 617.007 & 4,3 \\
\hline
\end{tabular}


garía nunca a ponerse en práctica. Sin embargo, en modo alguno se clarificaba cuáles fuesen a ser las funciones de cada una de las Cámaras o cuál fuese a ser su relación con el Presidente de la República, de modo que al elector se le colocaba en posición de elegir un Parlamento de cuya operatividad sabia bien poco.

Por lo que respecta a la elección presidencial, simultánea a la anterior, el sistema previsto sería el mayoritario a dos vueltas. Sólo lon lliescu, Ion Ratiu y Radu Campeanu lograrían las 100.000 firmas precisas para presentar su candidatura a un puesto cuyos perfiles eran entonces igualmente inciertos.

La campaña electoral que precedió a la votación se caracterizaría a un tiempo por su virulencia y por su monotonía. El continuo desfilar de partidos y más partidos por la prensa y la televisión estatales, proponiendo programas prácticamente idénticos, sólo se vería interrumpido por la noticias de incidentes violentos que salpicarían toda la campaña. Los choques entre la minoría húngara y los grupos nacionalistas en Transilvania se complementarían con los ataques a las sedes y los mítines de los partidos Campesino y Liberal en Moldavia y los enfrentamientos de las fuerzas de seguridad con los estudiantes en Bucarest y otras grandes ciudades, generándose en conjunto un clima de crispación bien poco recomendable. La responsabilidad en todo ello del FSN no es fácil de concretar, pero es innegable su pasividad a la hora de prevenir los incidentes violentos, su condescendencia en el sesgado tratamiento que de la información electoral darían durante la campaña la radio y la televisión públicas y su aprovechamiento continuado y privilegiado de los medios materiales y humanos del Estado en su campaña. Probablemente, el escrutinio se realizaría, llegado el momento, de forma limpia; pero con seguridad el ambiente que rodeó la consulta distó mucho de ser el idóneo.

Así las cosas, era poco probable que de las urnas saliese otra cosa que un triunfo rotundo del FSN. Y en efecto, éste se produciría de forma inapelable. La candidatura presidencial de lliescu (véase cuadro X) barrería con un $85 \%$ de los votos a las de sus dos oponentes, y las candidaturas del Frente a la Asamblea y al Senado conseguirian, respectivamente, los dos tercios y los tres cuartos de los escaños en juego. Del fracaso de la oposición, rotundo, sólo se salvaría la UDMR y, en parte, el PNL. Aquélla conseguiría colocarse como principal fuerza de la oposición, lo cual en cierto modo contribuiría a resaltar su carácter "problemático" en el seno de la sociedad rumana. Éste apenas conseguiría un exiguo $7 \%$, muy por delante, eso sí, del resto de sus competidores.

El respaldo de las distintas candidaturas presentaría particularidades regionales. Así, mientras que en Moldavia, Oltenia y Muntenia el FSN 
obtendría resultados casi aclamatorios, en Bucarest su apoyo sería sensiblemente menor, y en Transilvania quedaría en minoría ante el resto de los partidos y particularmente ante la UDMR, que con una campaña eficiente y unos candidatos de prestigio se haría con el voto de la inmensa mayoría de los húngaros.

Tras la elecciones, y con lliescu y Roman confirmados en sus puestos, el FSN se plantearía como objetivo inmediato la apertura de Rumanía a Occidente y la captación de inversiones que le permitiesen el preciso despegue económico. Sin embargo, la sombra del fraude electoral supondría un baldón sobre la legitimidad del nuevo gobierno, que la dureza con la que serían reprimidos los posteriores movimientos de protesta no haría sino agrandar. Durante meses Rumanía navegaría por una forma de populismo que, si bien estaba lejos del totalitarismo de Ceausescu, tampoco parecía encajar demasiado bien en lo que entendemos por democracia pluralista.

\section{LA ANTIGUA UNIÓN SOVIÉTICA: EL CAMINO HACIA LA DEMOCRACIA Y HACIA LA DISGREGACIÓN}

La elección en marzo de 1989 del recién creado Congreso de los Diputados del Pueblo de la URSS, en un ambiente no enteramente pluralista, pero sí palpablemente distinto del de anteriores procesos electorales, acabaría constituyendo el auténtico pistoletazo de salida de un proceso democratizador tan extenso como profundo. Afirmar que los resultados de la consulta electoral constituyeron para el todopoderoso Partido Comunista de la Unión Soviética una palmaria derrota sería probablemente exagerado. Pero resulta innegable que los procesos electorales de la primavera de 1989 generaron en el hasta entonces apático electorado soviético una cierta inquietud política, unida a una cada vez mayor convicción de que era factible cambiar el sistema político vigente valiéndose de la antes inútil mecánica electoral. Teniendo en cuenta que además fomentaron la aparición en el mapa político soviético de corrientes de opinión tenuemente organizadas, y que en ellas candidatos independientes o abiertamente disidentes lograron llamativas victorias frente a hombres clave del aparato del partido, no cabe sino concluir que éstas resultarían ser el primer hito de la posterior democratización de la vida política soviética.

Pues bien: el segundo de esos hitos lo constituirían las elecciones que durante prácticamente todo el año 1990 se sucederían en las distin- 
tas Repúblicas de la Unión para la renovación de los correspondientes órganos de poder local y republicano, esto es, para la renovación de los soviets de provincia, ciudad y distrito, de los soviets supremos de las Repúblicas y, en el caso ruso, del Congreso de los Diputados de Rusia.

La legislación aplicable en estos procesos resultaría ser de competencia de las propias Repúblicas y no de la Unión. Ello propiciaría la aparición de una normativa electoral heterogénea, la cual, aplicada sobre una realidad política igualmente diversa, daría como fruto una larga serie de procesos electorales (véase cuadro $\mathrm{XI}$ ) desacompasados en el tiempo y divergentes en cuanto a su resultado y a su democraticidad. Un análisis comparado de éstos probablemente permitiría agruparlos en tres grandes bloques.

De una parte nos encontraríamos con las elecciones verificadas en las Repúblicas de Turkmenistán, Uzbekistán, Kirguizistán, Tajikistán, Kazajhstán y Azerbaiján -las Repúblicas asiáticas, en suma-, en las que la absoluta hegemonía del aparato del PCUS y la falta de tradiciones democráticas y de fuerzas disidentes estructuradas harian de estos procesos algo escasamente distinto de experiencias anteriores. Además, la mayor parte de estas consultas se celebrarían con anterioridad a la trascendental reforma constitucional del 14 de marzo de 1990, lo que equivale a decir que se desarrollarían en un marco legal aún totalitario en el que al PCUS le era reconocido un papel privilegiado incompatible con las más elementales exigencias democráticas. De hecho, en muchos lugares las autoridades comunistas seguirían haciendo uso de su poder para desincentivar a los posibles opositores o plantearles insalvables trabas burocráticas, relativizando de este modo los ya escasos resquicios de libertad. Prueba de todo ello sería el hecho de que en estas Repúblicas se diesen a un tiempo los mayores índices de participación y los menores índices de competitividad, y que además en algún caso los escaños sin disputa alcanzasen la cuarta o incluso la tercera parte de los existentes.

En un segundo bloque de Repúblicas - caso de Moldavia, Bielorrusia, Rusia o Ucrania-, las prácticas obstaculizadoras de la administración y la escasa democraticidad del marco legal aplicable tropezarian con la existencia de una superior conciencia democrática y una oposición un tanto más estructurada, que sería capaz a la postre de arrancar el voto de importantes sectores de población. Así, podría estimarse que grupos como Rusia Democrática, el Frente Popular de Moldavia, el Club Democrático de Bielorrusia o los nacionalistas ucranianos de Rukh conseguirían en sus respectivas Repúblicas porcentajes de votos que oscilarían entre el 25 y el $35 \%$. Ello permitiría el acceso a las correspondientes Cámaras de minorías disidentes sumamente dinámicas, que, puestas en contacto con los sectores más críticos del aparato comunista y con los candidatos 


\section{Cuadro XI}

\section{URSS}

\section{Elecciones a los Soviets o Consejos Supremos, o Congresos}

de los Diputados del Pueblo de las Repúblicas Federadas

\begin{tabular}{|c|c|c|c|c|c|}
\hline Fecha & República & \% participación & $\begin{array}{c}\text { Ratio } \\
\text { cand/esc. }\end{array}$ & $\begin{array}{l}\text { \% esc. no } \\
\text { disputad. }\end{array}$ & $\begin{array}{l}\text { Representación aprox. } \\
\text { de grupos opositores }\end{array}$ \\
\hline 7 de enero de 1990 & Turkmenistán & 93,6 & 3,0 & 6,2 & Ninguna \\
\hline 18 de febrero de 1990 & Uzbekistán & 93,5 & 2,1 & 34,8 & Ninguna \\
\hline 24 de febrero de 1990 & Lituania & 75 & 3,3 & 5,6 & Sajudis: $73 \%$ \\
\hline 25 de febrero de 1990 & Kirguizistán & 92,0 & 2,5 & 24,5 & Ninguna \\
\hline 25 de febrero de 1990 & Tajikistán & 91,3 & 4,5 & 2,1 & Ninguna \\
\hline 25 de febrero de 1990 & Moldavia & 83,4 & $?$ & 1,8 & Frente Popular: $25 \%$ \\
\hline 4 de marzo de 1990 & Bielorrusia & 86,5 & 5,4 & 6,4 & Club Democrático: $30 \%$ \\
\hline 4 de marzo de 1990 & Rusia & 77,0 & 6,2 & 3,0 & Rusia Democrática: $30 \%$ \\
\hline 4 de marzo de 1990 & Ucrania & 84,7 & 6,4 & 0,8 & Bloque Democrático: $35 \%$ \\
\hline 18 de marzo de 1990 & Estonia & 78,2 & 3,7 & 0 & Frente Popular: $60 \%$ \\
\hline 18 de marzo de 1990 & Letonia & 81,2 & 1,9 & 26,3 & Frente Popular: $65 \%$ \\
\hline 25 de marzo de 1990 & Kazajhstán & 84,0 & 3,8 & 10,0 & Independientes: $5,6 \%$ \\
\hline 20 de mayo de 1990 & Armenia & 60,4 & 5,3 & $?$ & Mayoría \\
\hline 2 de septiembre de 1990 & Azerbaiján & $?$ & $?$ & $?$ & Frente Popular: $30 \%$ \\
\hline 28 de octubre de 1990 & Georgia & $?$ & 7,9 & $?$ & Georgia Libre: $54 \%$ \\
\hline
\end{tabular}


independientes, acabarían conformando mayorías bien lejanas de la estricta ortodoxia comunista.

Finalmente, las elecciones desarrolladas en las Repúblicas bálticas y en las caucásicas de Armenia y Georgia se verificarían en un ambiente extremadamente politizado y en un marco legal un tanto más aperturista. Letonia y Lituania no sólo habían procedido en diciembre del año anterior a derogar las disposiciones constitucionales que garantizaban en sus territorios el rol dirigente del partido -en Estonia la medida no se tomaría hasta enero-, sino que además contaban con una oposición nacionalista firmemente asentada y en acelerado proceso de organización. Si a eso hemos de añadir la existencia de profundas divisiones en el seno del Partido Comunista de esas Repúblicas, fragmentado entre partidarios del independentismo y unionistas, el conjunto nos ofrece un panorama bien distinto del anterior, en donde las posibilidades democratizadoras eran sin duda mayores y la competitividad enorme. En Georgia, la demora de las elecciones hasta finales de octubre permitiría a los partidos de la oposición organizarse de forma más consistente e incluso forzar al Partido Comunista a aprobar un sistema electoral proporcional y razonablemente democrático. Todo ello, unido a los éxitos que los distintos grupos opositores habían venido cosechando a lo largo del año, haría inevitable la arrolladora victoria del grupo ultranacionalista Georgia Libre, dirigido por el escritor Zviad Gamsajurdia, que se convertiría así en presidente de la República. Por último, en Armenia las elecciones se verificarían bajo la vigencia de la Ley Marcial, lo que arrojaría índices de participación muy bajos y numerosas elecciones inválidas por falta de votantes. Sin embargo, los nacionalistas del Comité Karabakh obtendrían apreciables resultados que, como en los casos anteriores, contribuirían a despejar el camino hacia la independencia.

Todo ello nos permitiría concluir que, celebradas las correspondientes elecciones, al menos cinco Repúblicas de la Unión -Estonia, Letonia, Lituania, Armenia y Georgia, esto es, las bálticas y dos de las transcaucásicas-contaban con mayorías parlamentarías opositoras y de signo marcadamente nacionalista, mientras que en otras cuatro -Moldavia, más las eslavas, esto es, Rusia, Bielorrusia y Ucrania- los grupos opositores, aun en minoría, ocupaban importantes parcelas parlamentarias. En el resto, es decir, en las Repúblicas del Asia soviética, la situación política permanecía aún bajo el control de los sectores más continuistas del partido. Con todo, resulta casi imposible hacer un mapa más detallado del panorama político soviético. Y ello por al menos cuatro motivos. A saber:

a) Por la enorme diversidad, heterogeneidad y desorganización de la mayor parte de las fuerzas políticas de la oposición, que haría a veces imposible su identificación y su ubicación política. 
b) Por la propia mecánica del sistema electoral, que, al partir en la mayor parte de los casos del tradicional sistema soviético de mayoría absoluta en distritos uninominales a dos o más vueltas, convertía en infructuoso todo intento de hallar nexos de unión entre los distintos candidatos - cuyas adscripciones políticas rara vez podian hacerse constar en la papeleta-, al tiempo que hacía difícil averiguar el resultado final de las elecciones, toda vez que éstas a veces se prolongaban durante meses al producirse la anulación de los escrutinios en los que no había participado el número suficiente de votantes o ninguno había obtenido la mayoría de votos precisa. Además, la propia dinámica del principio mayoritario hacía que se produjeran importantes divergencias entre el reparto de escaños parlamentarios y el previo reparto de votos, con lo que a las dificultades que entrañaba averiguar cuál es la composición real de la Cámara había que añadir las de averiguar cuál había sido la actitud última de los electores.

c) Por la misma falta de cultura democrática de buena parte de la sociedad soviética, así como de transparencia y democraticidad del propio proceso electoral, que hizo que todos los datos que finalmente pudieron llegar a obtenerse hubiesen ser analizados con notables dosis de escepticismo, ante la posibilidad de que nos hallásemos ante poco más que una ficción democrática.

y d) Por la extremada inestabilidad, no sólo del electorado sino también de la clase política soviética. Ello hacía imprevisibles sus posicionamientos futuros, y más si tenemos en cuenta el continuo proceso de cambio que se estaba viviendo en el seno del PCUS, que en poco tiempo pasaría de ser el bastión de la ortodoxia marxista-leninista a convertirse en uno de los principales motores de su transformación. No es de extrañar por esto que órganos plenamente dominados por cuadros del partido se convirtiesen en poco tiempo en auténticas vanguardias del cambio, que muchos de los principales líderes del reformismo fuesen a la vez militantes activos del partido o incluso que más de una fuerza opositora hubiese partido en sus orígenes de los propios círculos del PCUS.

Aun así, el análisis de los procesos electorales vividos en las Repúblicas con mayor concienciación política - es el caso de las Repúblicas Bálticas- no deja de resultar sugestivo, y merece una atención especial.

\section{A) LITUANIA}

Por lo que respecta a Lituania, las elecciones se verificarian por el típico sistema soviético de mayoría absoluta en distritos uninominales. Para resultar elegido, el candidato precisaba haber obtenido la mitad más uno de los votos, de modo que si ninguno los obtenía los dos más vota- 
dos pasaban a una segunda vuelta. Sin embargo, si en la primera vuelta

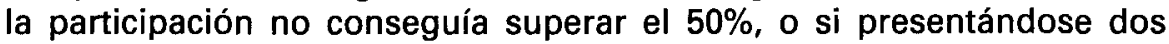
candidatos ninguno lograba la mitad de los votos (en realidad, el elector no votaba por el candidato que prefiere, sino que tachaba al que rechazaba, pudiendo rechazarlos a todos), se procedía a repetir de nuevo la elección, incluso con la presentación de nuevos candidatos.

La presentación de candidaturas, prácticamente libre, no arrojaría, sin embargo, una ratio candidato/escaño demasiado alta. Ello sería resultado, sin duda, de la clara polarización de los electores lituanos en torno al tema crucial de su independencia nacional, que convertía en secundario cualquier posicionamiento que no hiciese referencia a tal cuestión. Así, resultarían accidentales en buena parte de los casos las adscripciones partidistas de los distintos candidatos, toda vez que el electorado los valoraría fundamentalmente por lo que respectase a su postura independentista o pro-soviética. Ello explicaria la existencia en muchos casos de candidaturas apoyadas por varias fuerzas, o que la presentación de candidaturas múltiples sólo se verificase en los distritos en los que la victoria era segura o no había competencia.

Los partidarios de la continuidad de Lituania en la URSS -mayoritariamente inmigrantes rusos y polacos- se agruparían en torno al PCUS. En cambio, los partidarios de la independencia lituana se repartirían entre un abanico de fuerzas que iría desde el Partido Cristianodemócrata hasta el Partido Comunista Lituano de Algirdas Brazauskas, fruto de una escisión del PCUS que había dejado a éste fuertemente mermado. Sin embargo, el principal protagonista de estas elecciones sería el Sájudis, una especie de gran movimiento (Sájudis significa, de hecho, movimiento) situado por encima de los partidos y destinado a coadyuvar en todo lo que fuese la independencia de esta República. Así, el Sájudis presentaría candidatos propios para una serie de escaños, pero apoyaría a los de otros partidos cuando los considerase aceptables o simplemente cuando éstos estuviesen compatibilizando su pertenencia al partido en cuestión con su militancia en el Sájudis.

Los resultados electorales (véase cuadro XII) resultarían una inapelable victoria para la oposición democrática e independentista; 92 de los 147 candidatos apoyados por el Sájudis obtendrían escaño, repartiéndose éstos entre cristianodemócratas, demócratas, verdes, socialdemócratas, comunistas del PCL e independientes. Por contra, los unionistas apenas contarían con los parlamentarios del PCUS y con alguno de los del PCL, no constituyendo en ningún caso un peligro parlamentario serio para la independencia lituana, que sería proclamada sin dilación el 11 de marzo. Como presidente de la República, el Parlamento procedería a elegir al conocido músico y disidente Vytautas Landsbergis, líder del Sájudis. 


\section{Cuadro XIII \\ ESTONIA \\ Elecciones parlamentarias \\ 18 de marzo de 1990}

Participación: aprox. 910.000 electores $(78,2 \%)$

Consejo Supremo: 105 escaños

\begin{tabular}{|c|c|}
\hline Candidatos nominados ...................... & 536 \\
\hline Candidatos concurrentes ....... & 392 \\
\hline 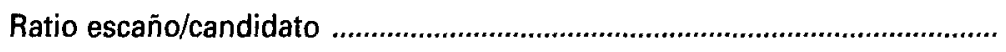 & 37 \\
\hline \% Población de origen estoniano & 61,2 \\
\hline 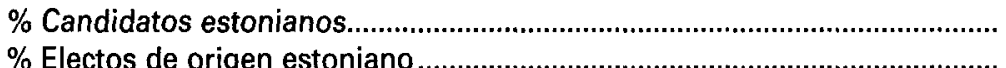 & $\begin{array}{l}73 \\
76\end{array}$ \\
\hline
\end{tabular}

Independentistas

Frente Popular Estoniano.........................................................................

Unión Estoniana de Colectivos de Trabajadores...................................... $\quad 10$

Estonia Libre (Comunistas pro-independentistas) ....................................

Partido Comunista de Estonia ....................................................................

Verdes...............................................................................................

Pro-soviéticos

Consejo Unido de Colectivos de Trabajo (comunistas pro-soviéticos)... $\quad 40$

Partido Democrático (Liberales rusos) ...................................................

éstas un poderoso elemento para disminuir la proporcionalidad del sistema por el simple procedimiento de primar la constitución de distritos pequeños o incluso uninominales. Por lo demás, el sistema contenía rigurosos requisitos de residencia para los candidatos, privaba del sufragio a quienes no pudiesen acreditar al menos diez años de residencia en Estonia, fijaba requisitos para ser nominados como candidato extremadamente laxos y, como ocurriría en otros lugares, tampoco les permitía a los candidatos especificar en la papeleta su adscripción política.

La principal disputa de cara a la urnas se plantearia también aquí entre independentistas y pro-soviéticos. Los primeros se reunirían en torno al Frente Popular Estoniano, con el cual colaborarían una larga serie de partidos menores pero también la importante escisión nacionalista del Partido Comunista Estoniano. El sector pro-soviético se alinearia, en cambio, en el Consejo Unido de Colectivos de Trabajo y en el Partido Democrático. 


\section{Cuadro XIV \\ LETONIA \\ Elecciones parlamentarias \\ 1. ${ }^{a}$ vuelta: 18 de marzo de 1990.}

2. ${ }^{a}$ y ulteriores vueltas: 25 de marzo, 1 de abril y 29 e abril de 1990.

Participación: $1 .^{\Xi}$ vuelta: aprox. 1.600 .000 electores $(81,2)$

Consejo Supremo: 201 escaños

Candidatos nominados

Candidatos concurrentes

Ratio escaño/candidato

$\%$ Población de origen letón.

Independentistas (en su mayoría integrantes del Frente Popular de Letonia)

Partido Comunista Letón

Movimiento Nacional para la Independencia de Letonia.

Unión Campesina

Partido Verde

Partido Obrero Socialdemócrata.

Independientes.

Pro-soviéticos

Frente Internacionalista.

Partido Comunista de la Unión Soviética

Independientes.

La victoria de los candidatos independentistas (véase cuadro XIII) resultaría bien holgada, pudiéndose afirmar que acabarían contando con un número de escaños lindante con los dos tercios, aunque, como en el caso lituano, la práctica de apoyar conjuntamente a un mismo candidato y la propia dinámica del sistema electoral harían difícil una tabulación fiable de los resultados. Con todo, los resultados finales arrojarian el dato sorprendente de que importantes sectores de población de origen étnico no estoniano habían acabado apoyando las candidaturas independentistas, toda vez que, siendo estoniana tan sólo el $61 \%$ de la población de la República, el porcentaje de estonianos entre los parlamentarios electos superaría el $75 \%$. 
A la vista del éxito obtenido, no tardaría en iniciarse el camino hacia la independencia. Su primer jalón lo constituiría la declaración del 30 de marzo, en la que el recién elegido Consejo Supremo de Estonia proclamaría, por 73 votos a favor y sólo 8 en contra, la independencia nacional de la República.

\section{C) LETONIA}

Por lo que respecta a Letonia, el sistema electoral empleado sería nuevamente el mayoritario, pero en esta ocasión lo sería con un bajísimo nivel de competitividad $y$ un alto porcentaje de escaños sin disputa.

También en este caso los candidatos independentistas se harían con la mayor parte de los escaños, y como en las demás ocasiones lo harían merced al doble apoyo de los partidos de origen y del Frente Popular de Letonia. Así, los candidatos apoyados por esta última organización obtendrían un total de 111 escaños, que, unidos a los de otras formaciones independentistas no apoyadas por el Frente, elevarían el número de partidarios de la independencia letona hasta 131. Por su parte, los importantes sectores pro-soviéticos - sólo el $51 \%$ de los habitantes de la República es de origen letón- se agruparían en torno al PCUS y al Frente Internacionalista, que juntos conseguirían medio centenar de escaños. Como en el caso de Estonia, no dejaría de sorprender el enorme desfase entre el porcentaje de población autóctona y el número de los parlamentarios de origen letón (véase cuadro XIV).

Al igual que harían las otras dos Repúblicas Bálticas, también Letonia aprobaría, el 4 de mayo de 1990, su declaración de independencia. Pocos días después, el 13 de mayo, Estonia, Letonia y Lituania acordarían la reconstitución del Consejo Nacional Báltico como órgano de coordinación de sus respectivas políticas, encaminado prioritariamente a la consolidación de su vía hacia la independencia.

\section{LA ANTIGUA YUGOSLAVIA: LOS PRECURSORES DE LA DEMOCRATIZACIÓN Y EL ÚLTIMO REDUCTO DEL LENINISMO}

El rasgo más llamativo de la evolución política de Yugoslavia durante el año 1990 lo constituye sin duda el progresivo ahondamiento en las diferencias nacionales que el proceso democratizador ha ido paulatinamente generando. 0 , por explicarlo en términos más precisos, el he- 
cho de que las siempre tensas relaciones entre las distintas Repúblicas integrantes de la Federación Yugoslava se crispasen hasta el punto de desembocar en la ruptura, aparecería cada vez con mayor nitidez como una consecuencia - entre otras- de las serias diferencias que en el desarrollo de sus procesos democratizadores comenzarian a presentar unas y otras Repúblicas.

Este proceso de ruptura arranca sin duda del XIV Congreso de la Liga de los Comunistas de Yugoslavia, celebrado a finales de enero de 1990. En él, la delegación eslovena, encabezada por Milan Kucan, propondria una amplia serie de medidas destinadas a democratizar la LCY, medidas cuyo rechazo frontal por el grueso del partido -1.159 votos en contra por apenas 169 a favor- provocaría el abandono de la delegación eslovena y la ruptura de facto de la Liga. A partir de entonces, los acontecimientos se precipitarían. Eslovenia y Croacia, las Repúblicas más abiertas, más occidentalizadas y de mayor nivel de vida, apostarian inmediatamente por la plena democratización, convocando para el mes de abril elecciones a sus Parlamentos. Ante ello, Bosnia y Macedonia mantendrían una actitud expectante, mientras que Serbia, y con ella Montenegro, comenzaría a desconfiar crecientemente, optando por desarrollar procesos sólo aparentemente democráticos

\section{A) ESLOVENIA}

Las elecciones parlamentarias eslovenas se saldarian Ivéase cuadro $X V$ ) con un rotundo triunfo de la coalición Demos, formada por un amplísimo abanico de fuerzas que iban desde los democristianos a los socialdemócratas, pasando por los ecologistas y los agrarios. Con casi el $50 \%$ de los votos, Demos rebasaría sobradamente a su principal contrincante, el Partido para la Renovación Democrática, heredero reformado de la antigua Liga de los Comunistas de Eslovenia. Sin embargo, en las elecciones presidenciales, simultáneas, el antiguo lider comunista Milan Kucan sacaría un buen partido de su imagen reformista, venciendo en la segunda vuelta al candidato de Demos Joze Pucnik, un profesor de filosofía con una larga trayectoria de disidencia, cárcel y exilio. Se forzaría así una cohabitación que no parece haber funcionado mal.

La composición del Parlamento de Ljubljana se completaría con una escasa presencia de diputados del Partido Liberal-Liga de la Juventud Socialista, formación con una cierta similitud en cuanto a sus formas con la Fidesz húngara, así como de representantes de la Alianza Socialista. Por último, las también importantes elecciones para la Presidencia colegiada de la República acabarían de complicar el panorama político esloveno. Junto con Kucan, pasarían a integrar este órgano Ciril Zlobec 


\section{Cuadro XV \\ ESLOVENIA \\ Elecciones parlamentarias y presidenciales}

1. ${ }^{a}$ vuelta: 8 de abril de 1990. 2. ${ }^{a}$ vuelta: 22 de abril de 1990.

Participación: $80 \%$

Asamblea: 240 escaños (Cámara Sociopolítica: 80;

Cámara del Trabajo Asociado: 80; Cámara de los Municipios: 80)

\begin{tabular}{|c|c|c|c|c|}
\hline & $\begin{array}{l}\text { \% votos } \\
\text { Cám. S-P }\end{array}$ & $\begin{array}{l}\text { Escaños } \\
\text { Cám. S-P }\end{array}$ & $\begin{array}{l}\text { Escaños } \\
\text { Cám. TA }\end{array}$ & $\begin{array}{l}\text { Escaños } \\
\text { Cám. M }\end{array}$ \\
\hline Demos & 55,0 & 47 & 29 & 51 \\
\hline SKD (Cristianodemócratas Eslovenos) .... & 12,9 & 11 & & \\
\hline SKZ (Liga Campesina Eslovena)................ & 12,5 & 11 & & \\
\hline SDZ (Liga Democrática Eslovena) ............. & 9,9 & 8 & & \\
\hline ZS (Verdes de Eslovenia) .......................... & 8,9 & 8 & & \\
\hline SDZS (Liga Socialdemócrata) ..................... & 7,3 & 6 & & \\
\hline SOS (Liga de los Artesanos Eslovenos)... & 3,5 & 3 & & \\
\hline ZKS/SDP (Partido para la Transf. Dem./Liga & & & & \\
\hline de los Com.) & 17 & 14 & 5 & 5 \\
\hline ZKM/LS (Partido Liberal Democrático)............ & 15 & 12 & 9 & 16 \\
\hline SZS/SZDL (Partido Socialista Esloveno) ......... & 5 & 5 & 3 & 5 \\
\hline $\begin{array}{l}\text { Escaños reservados para las minorías } \\
\text { italiana y húngara }\end{array}$ & - & 2 & - & 2 \\
\hline 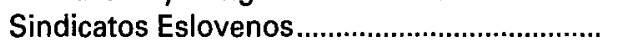 & - & - & 7 & - \\
\hline Cámara de Comercio Eslovena............................ & - & - & 7 & - \\
\hline 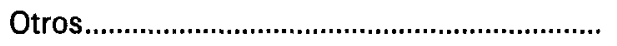 & - & - & 20 & - \\
\hline Independientes & - & - & - & 1 \\
\hline
\end{tabular}

Presidencia de la República

\begin{tabular}{|c|c|c|}
\hline 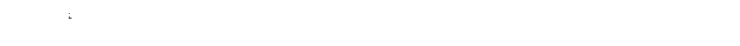 & $\%$ votos $1 .{ }^{a} v$ & $\%$ votos $2 \cdot{ }^{a} v$ \\
\hline 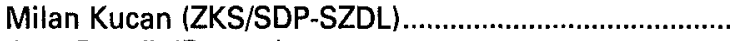 & 44,4 & 58,3 \\
\hline Joze Pucnik (Demos) & 26,6 & 41,7 \\
\hline Iván Kramberger (independiente) ..................................... & 18,5 & - \\
\hline Marko Demsar (P. Liberal-Liga de la Juventud Soc.) .... & 10,5 & - \\
\hline
\end{tabular}

(Alianza Socialista), Ivan Oman (Demos), Matjaz Kmecl (PTD-LCE) y Dusan Plut (Demos). De este modo, tanto Demos como el Partido para la Transformación Demócratica pasaban a controlar dos puestos, quedando en el fiel de la balanza - pero más cerca de los comunistas reformados que de los opositores- el representante socialista. 


\section{B) CROACIA}

En Croacia, las elecciones parlamentarias se celebrarían pocos días después en un ambiente de exaltado nacionalismo, coincidendo con las mismas también las municipales. El sistema electoral empleado, mayoritario a dos vueltas, se vería complicado por la presencia de reminiscencias corporativas, toda vez que el Parlamento croata permanecía aún compuesto por tres Cámaras - la Cámara política, la de los municipios y la del trabajo-y no todos los ciudadanos disponían de idénticos derechos de sufragio.

En este caso, varias fuerzas opositoras de signo marcadamente nacionalista habían conseguido converger en una formación unitaria -la Comunidad Demócrata Croata (HDZ) - que, bajo la dirección del ex-general del ejército federal e historiador Franjo Tudjman, barrería sin complicaciones al resto de las fuerzas concurrentes, y en particular a los comunistas reformistas del Partido para la Transformación Democrática (véase cuadro XVI). La HDZ resultaría ser una heterogénea alianza de nacionalistas, campesinos y democristianos, pero la fuerte personalidad de Tudjman y su satisfactoria identificación con las mismas aspiraciones independentistas de Croacia multiplicarían su fuerza ante las urnas. La HDZ reivindicaría en su programa político la soberanía nacional de Croacia y su derecho a separarse de la Federación Yugoslava, la necesidad de una democratización profunda y la integración política y económica en Europa. La Alianza para el Acuerdo Nacional, también opositora e integrada por intelectuales disidentes del titismo y por un amplio abanico de pequeños partidos - social-liberales, democristianos, socialdemócratas y nacionalistas-, quedaría en un discreto segundo plano. El Partido Demócrata Serbio, defensor de los derechos de las minorías serbias en Croacia, quedaría por diversos motivos fuera del Parlamento, mas no por ello fuera del juego político. En cuanto a las elecciones presidenciales, Tudjman no tendría problemas en imponerse ampliamente, tanto a Ivice Racan, del Partido de la Transformación Democrática, como a Ivo Druzic, de la Coalición para el Acuerdo Nacional. El abogado Stjepan Mesic sería el encargado de formar el primer gobierno democrático de Croacia.

En suma, las elecciones eslovenas y croatas supondrian la puntilla para la LCY. Rota desde enero y desplazada radicalmente del poder en las dos Repúblicas que ya habían elegido sus Parlamentos, la Liga reanudaría su interrumpido Congreso a finales de mayo para certificar de hecho su desaparición, no sólo como guía ideológica del Estado sino incluso como fuerza política unitaria. Sobre sus ruinas se ensayaría la creación de un Partido Socialista reformado, bajo la denominación ya conocida de Partido para la Transformación Democrática, al tiempo que el Primer Ministro Federal Ante Markovic auspiciaba la creación de un partido panyugoslavo bajo la denominación de Alianza de Fuerzas Reformistas y en Serbia los sectores más duros de la Liga se agrupaban bajo el liderazgo de Slobodan Milosevic en el Partido Socialista Serbio. 


\section{Cuadro XVI \\ CROACIA \\ Elecciones parlamentarias}

1. ${ }^{a}$ vuelta: 22 de abril de 1990. 2. vuelta: 29 de abril de 1990.

Participación: 84-76\% (1. ${ }^{\mathrm{a}}$ vuelta), 74-66\% (2. ${ }^{\mathrm{a}}$ vuelta)

Sabor: 356 escaños [Cámara Sociopolítica (DPV): 80;

Cámara del Trabajo (VUR): 160; Cámara de los Municipios (VO): 116]

\begin{tabular}{|c|c|c|c|c|}
\hline & $\begin{array}{c}\text { \% votos } \\
\text { DPV }\end{array}$ & $\begin{array}{c}\text { Escaños } \\
\text { DPV }\end{array}$ & $\begin{array}{c}\text { Escaños } \\
\text { VUR }\end{array}$ & $\begin{array}{c}\text { Escaños } \\
\quad \text { Vo }\end{array}$ \\
\hline HDZ (Comunidad Demócrata Croata) .............. & 40,0 & 54 & 83 & 68 \\
\hline SKH/SDP (Liga Com./P. de la Transf. Dem.).. & 22,6 & 12 & 38 & 23 \\
\hline KNS (Coalición por el Acuerdo Popular) ........ & 10,5 & 3 & 6 & 2 \\
\hline SDS (Partido Serbio Democrático) ....................... & 1,5 & 1 & 1 & 3 \\
\hline HDS (Partido Democrático de Croacia) ........... & 3,8 & 0 & 7 & 3 \\
\hline HSS (Partido Campesino de Croacia) .............. & 01 & 0 & 1 & 0 \\
\hline SSOH (Liga de la Juventud Socialista) ............ & 0,04 & 0 & 1 & 0 \\
\hline SKH/SDP-SSH (SKH/SDP-Partido Socialista). & 4,3 & 4 & 4 & 9 \\
\hline SS-SSH (P. Socialdemócrata-P. Socialista) ... & 6,2 & 2 & 1 & 1 \\
\hline SKH/SDP-SSH-SSOH & - & 1 & 1 & 1 \\
\hline HDZ-HSS ........................ & 0,7 & 1 & 0 & 1 \\
\hline ZAS-SKH/SDP (Acción Verde Split-SKH/SDP) & 0,5 & 1 & 0 & 0 \\
\hline 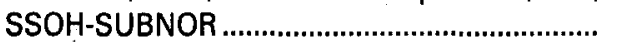 & - & 0 & 0 & 2 \\
\hline HDZ-HSLS (HDZ-Partido Social-Liberal).......... & 0,34 & 0 & 0 & 2 \\
\hline 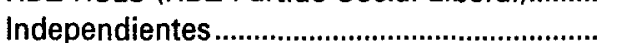 & 3,9 & 1 & 12 & 0 \\
\hline Udruz. Samost. Privr. Durdevac ........................ & - & 0 & 1 & 0 \\
\hline
\end{tabular}

Sin embargo, el ejemplo democratizador de eslovenos y croatas tardaría bastantes meses en ser imitado en el resto de la Federación. Así Macedonia y Bosnia no celebrarían sus elecciones hasta noviembre de 1990, mientras que Serbia y Montenegro, las Repúblicas más conservadoras, las demorarían hasta mediados de diciembre. Este dato, y sobre todo los muy divergentes resultados de unas y otras consultas, generarian a corto plazo ese desfase al que se hacía referencia en un principio, dando lugar a la aparición de tres Yugoslavias: una, la integrada por Eslovenia y Croacia, abiertamente democrática - aunque en modo alguno libre de tentaciones autoritarias - y claramente encaminada hacia la secesión; otra, integrada por Macedonia y Bosnia, sumida en un conflicto interétnico sin salida aparente, y una tercera, compuesta por Serbia y Montenegro, escasamante democrática y decidida a mantener su posición de hegemonía dentro de la Federación, o como mínimo a obtener contrapartidas de materializarse la anunciada ruptura. 


\section{C) MACEDONIA}

Las elecciones en Macedonia (véase cuadro XVII) darían un cierto respiro tanto a los socialistas reformados del Partido para la Transformación Democrática - que serían la segunda fuerza más votada - como a los seguidores del Primer Ministro Markovic, que alcanzarían una modesta cuota de representación. Pero, en todo caso, la victoria se decantaría del lado del nacionalismo populista de VMRO, que además barrería de forma radical al Movimiento Pan-Macedonio, protagonista de los últimos años de la clandestinidad y principal constructor ideológico del nacionalismo macedonio. Sumamente desconectado de la realidad social, el MAAK fracasaría por entero, dejando el liderazgo del movimiento independentista en manos del IMRO.

El panorama político de la nueva Macedonia se completaría con la significativa presencia en la cámara de las minorías albanesa - representada por el PDPM- y del más moderado Partido Socialista Macedonio. Como presidente sería elegido Kiro Gligorov, quien se vería obligado a contar para sus gabinetes con un amplio porcentaje de personalidades independientes ante la falta de claras mayorías en el Parlamento.

\section{D) BOSNIA-HERCEGOVINA}

Al contrario de lo que había ocurrido en Macedonia, las elecciones celebradas inmediatamente después en Bosnia-Hercegovina (véase cuadro XVIII) supondrían un serio revés para ambos partidos federalistas, que se tendrian que conformar con poco más de un $15 \%$ de los escaños en juego. Muy al contrario, los electores bosnios enviarían al Parlamento de Sarajevo una representación prácticamente fotográfica de la diversidad étnica de su república. Poblada ésta por un $40 \%$ de musulmanes, un $32 \%$ de serbios y un $18 \%$ de croatas, las candidaturas de la Acción Democrática Musulmana obtendrían un $41,25 \%$ de los votos, las del Partido Demócrata Serbio un $34,50 \%$ y las de la Comunidad Demócrata Croata un $20,75 \%$.

Los siete puestos de la presidencia colegiada de la República, que constitucionalmente se reparten por igual entre las tres etnias principales, con un séptimo puesto para las demás nacionalidades, serían disputados por un total de 28 candidatos. A la postre, los siete electos designarían a su vez al musulmán Alija Izetbegovic para la Presidencia. Por último, y en un intento de mantener a Bosnia lejos de los conflictos étnicos que ya comenzaban a apuntar, los tres partidos vencedores acordarían la formación de un gobierno de concentración, así como el reparto equitativo de las carteras entre las diversas etnias. 


\section{Cuadro XVII \\ MACEDONIA \\ Elecciones parlamentarias}

3 Vueltas: 9 de noviembre, 25 de noviembre y 9 de diciembre de 1990.

Participación: $83,98 \%$

Sobranie: 120 escaños

N.ำ escaños

VMRO/DPMNE (Organización Revolucionaria Interior de Macedonia/

Partido Democrático para la Unidad Nacional Macedonia) .................. 38

SKM/PDP (Liga de los Comunistas de M.-Partido para la Transf. Dem.)... 31

PDPM (Partido para la Prosperidad Democrática)........................................ 17

SPM (Partido Socialista de Macedonia) ..........................................................

SJM (Partido de los Yugoslavos de Macedonia)........................................

PDP (Partido Nacional Demócrata) ......................................................... 1

PDPM-PDP .....................................................................................

SRSM-MDPSM (Alianza de Fuerzas Reformistas-MDPSM)........................ 6

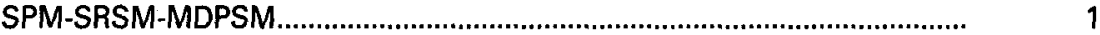

SPM-PCER (SPM-Partido para la Completa Emancipación de los Gitanos) 1

Independientes .............................................................................................. 3

\section{E) SERBIA}

Serbia demoraría hasta el 9 de diciembre sus elecciones, tanto parlamentarias como presidenciales. Éstas se celebrarán según un sistema de mayoría absoluta a dos o más vueltas, simultaneándose con las locales.

Los meses anteriores a la consulta se caracterizarian por una creciente tensión política. La oposición, tardíamente legalizada a finales de agosto, se desarrollaría de forma rápida, aunque caótica. Así, a comienzos de septiembre eran ya quince los partidos inscritos, y llegado el momento de la presentación de candidaturas, no menos de 40 concurririan a las elecciones, siendo 32 el número de candidatos a la Presidencia. Sin embargo, la pervivencia de prácticas totalitarias en el gobernante Partido Socialista Serbio (SPS) no cesaría de provocar incidentes. De entrada, la oposición se vería privada por completo de cualquier papel en la elaboración de la nueva Constitución serbia, que sería aprobada el 28 de septiembre de 1990. Además, a ésta tampoco le sería permitido mediar en la redacción de la Ley Electoral, que configuraría así un sistema a la medida del antiguo partido único, privando además a la oposición de recursos tan elementales como la posibilidad de comparecer ante las cámaras de 


\section{Cuadro XVIII \\ BOSNIA-HERCEGOVINA \\ Elecciones parlamentarias y a la Presidencia colectiva}

3 Vueltas: 18 de noviembre, 2 de diciembre y 9 de diciembre de 1990. Skupstina (240 escaños)

\begin{tabular}{|c|c|c|c|}
\hline & $\%$ votos & $\begin{array}{l}\text { Esc. Cam. } \\
\text { Ciudadana }\end{array}$ & $\begin{array}{l}\text { Esc. Cam. } \\
\text { Municipal }\end{array}$ \\
\hline SDA (Partido de Acción Democrática ....................... & 41,25 & 43 & 43 \\
\hline 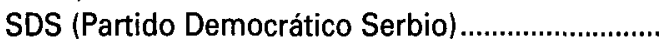 & 34,50 & 34 & 38 \\
\hline 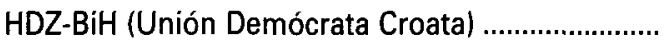 & 20,25 & 21 & 23 \\
\hline SK-BiH/SPD (Part. Transf. Dem./Liga de los Com.) & & 15 & 4 \\
\hline SRSJ-BiH (Alianza de Fuerzas Reformistas)............ & - & 12 & - \\
\hline MBO (Organización Musulmana-Bosnia) ................ & - & 2 & - \\
\hline DSS (Partido Democrático Socialista)....................... & - & 1 & 1 \\
\hline Otros & - & 2 & 1 \\
\hline
\end{tabular}

Presidencia colectiva

(Sólo candidatos electos)

\begin{tabular}{|c|c|c|c|}
\hline Grupo étnico & Candidato & Partido & $\%$ votos \\
\hline Musulmanes & Fikret Abdic & SDA & 44 \\
\hline$"$ & Alija Izetbegovic & SDA & 37 \\
\hline Serbios & Nikola Koljevic & SDS & 25 \\
\hline$"$ & Biljana Plavsic & SDS & 24 \\
\hline Croatas & Stjepan Kljuic & $\mathrm{HDZ}$ & 21 \\
\hline$"$ & Franjo Boras & HDZ & 19 \\
\hline Otros & Ejup Ganic & SDA & - \\
\hline
\end{tabular}

la televisión pública. Todo ello provocaría la organización de movilizaciones masivas a cargo del que ya se perfilaba como principal partido de la oposición, el nacionalista Movimiento para la Renovación Serbia (SPO), movilizaciones que apenas conseguirían un leve retraso en la celebración de los comicios y un muy tardío reconocimiento del derecho de las fuerzas opositoras a comparecer ante los medios de comunicación públicos.

El Movimiento para la Renovación Serbia, liderado por Vuk Draskovic - que con su poblada barba y sus largas melenas rizadas era la verdadera antítesis del siempre atildado Milosevic- plantearía ante el electorado un nacionalismo tan visceral como el que los socialistas serbios 


\section{Cuadro XIX \\ SERBIA \\ Elecciones parlamentarias}

1. ${ }^{a}$ vuelta: 9 de diciembre de 1990. 2. ${ }^{a}$ vuelta: 23 de diciembre de 1990. Participación: 1.ㄹ vuelta: $71,5 \%$. $2 .^{a}$ vuelta: $48,3 \%$

Skupstina: 250 escaños

\begin{tabular}{|c|c|}
\hline & N.ํoscaños \\
\hline SPS (Partido Socialista Serbio) ........ & 194 \\
\hline SPO (Movimiento para la Renovación Serbia) & 19 \\
\hline DZMV (Comunidad Democrática de los Húngaros de Voivodina)............... & 8 \\
\hline DS (Partido Democrático) & 7 \\
\hline SDA (Partido de Acción Democrática) & 3 \\
\hline StSSIjS (Unión de Campesinos Serbios) & 2 \\
\hline 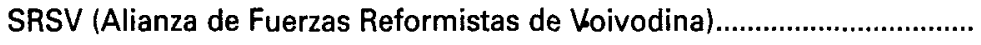 & 2 \\
\hline $\begin{array}{l}\text { Otros (Partido de los Yugoslavos, Reformista Democrático Musulmán, } \\
\text { Nacional Campesino, Democrático Serbio, de Acción Democrática, } \\
\text { Asociación de Iniciativa Democrática Yugoslava y Liga Democrática }\end{array}$ & \\
\hline 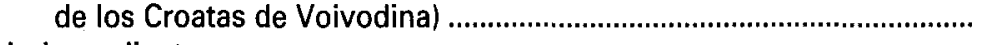 & 7 \\
\hline Independientes & 8 \\
\hline
\end{tabular}

Elecciones presidenciales

1. ${ }^{a}$ vuelta: 9 de diciembre de 1990 (no se precisó 2. vuelta)

\begin{tabular}{|c|c|}
\hline & $\%$ \\
\hline Slobodan Milosevic (SPS) & 65,34 \\
\hline Vuk Draskovic (SPO) & 16,40 \\
\hline Ivan Duric (SRS), & 5,52 \\
\hline Suleiman Ugljanin (SDA) & 2,18 \\
\hline
\end{tabular}

habia logrado popularizar, pero un tanto menos beligerante para con sus vecinos. Así, mientras Milosevic se oponía con rotundidad a la transformación de la Federación Yugoslava en una forma más laxa de asociación de Estados, al tiempo que reclamaba la necesidad de corregir las actuales fronteras serbias, para Draskovic la Confederación no dejaba de ser una posibilidad de futuro más, mientras que el replanteamiento de las fronteras constituiría con seguridad una inagotable fuente de problemas. Por lo demás, el nacionalismo del SPO era un nacionalismo de corte democrático, mientras que el de Milosevic no se alejaba demasiado de las viejas prácticas socialistas..., cosa que se revelaría sobradamente a lo largo de la campaña electoral. 
Por su parte, la comunidad albanesa, mayoritaria en la provincia ex-autónoma de Kosovo, propondría un boicot total a los comicios como respuesta a la decisión del Parlamento de Belgrado de derogar su Constitución y disolver su Parlamento, conviertiendo al Kosovo de hecho en un simple distrito administrativo serbio. La práctica totalidad de los partidos albaneses -entre ellos, la aparentemente mayoritaria Liga Democrática del Kosovo- recomendarían la abstención, de modo que, celebradas las elecciones, no más del $10 \%$ de los electores de esta región - los de etnia serbia - acudirían a las urnas, haciendo de los resultados de este territorio una mera ficción. Entre unos y otros, el Partido Democrático apostaría por la moderación e intentaría huir del nacionalismo como único argumento de peso político.

Los resultados de la primera vuelta (véase cuadro $X I X$ ) arrojarían una ventaja abismal en favor de Milosevic y el SPS. El líder socialista resultaría elegido presidente sin tener que acudir a la segunda vuelta, mientras que su partido se alzaría con la casi totalidad de los escaños decididos. Ello forzaría nuevas llamadas al boicot entre los líderes del SPO, convencidos de la existencia de una manipulación de votos a gran escala. Sin embargo, estas nuevas medidas no llegarían a ser efectivas, de modo que, llegada la segunda vuelta, la oposición no tendría más salida que participar y conformarse con una exigua representación que en conjunto no superaría el $20 \%$ del total de escaños.

\section{F) MONTENEGRO}

Por último, la República de Montenegro - la más próxima a los puntos de vista de Serbia de entre todas las componentes de la Federación-celebraría sus elecciones parlamentarias y presidenciales en idénticas fechas y con similares resultados. Como en Serbia, también aquí (véase cuadro $X X$ ) los comunistas reformados - pero aun así de fuerte impronta conservadora- se alzarían con un $58 \%$ de los votos y la mayoría de los escaños de la Cámara, dejando en un segundo plano a la Alianza de Fuerzas Reformistas de Ante Markovic, a la Coalición Democrática musulmana y al Partido Nacional, partidario de la fusión de Montenegro con Serbia. El candidato presidencial de los neocomunistas, Momir Bulatovic, lograría un resultado más abultado incluso que el de Milosevic.

El resultado de las elecciones en Montenegro vendría condicionado - quizás más que en ninguna otra parte- por la pervivencia de las estructuras del antiguo sistema de partido único. Mientras que el SKCG dispondría a su antojo de toda la maquinaria de la antigua Liga, fuerzas como la SRSCG o el Partido Nacional tendrían que instalar sus sedes de campaña en los mismos domicilios de sus líderes o en simples habitaciones de hotel. 


\section{Cuadro XX \\ MONTENEGRO \\ Elecciones parlamentarias y presidenciales}

1. ${ }^{a}$ vuelta: 9 de diciembre de 1990. 2. vuelta: 23 de diciembre de 1990.

Participación: 1. ${ }^{a}$ vuelta: $65,8 \%$. 2. vuelta: $48,3 \%$

Skupstina: 125 escaños

\begin{tabular}{|c|c|c|}
\hline & N. ${ }^{o}$ esc. $1 . \stackrel{g}{ } \mathrm{~V}$ & N. ${ }^{o}$ esc. total \\
\hline SKCG (Liga de los Comunistas de Montenegro).. & 83 & 83 \\
\hline SRSCG (Alianza de Fuerzas Reformistas)...................... & 7 & 17 \\
\hline DK (Coalición Democrática [min. musulmana])............. & 9 & 13 \\
\hline 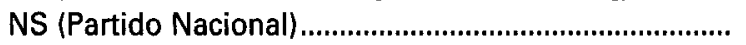 & 8 & 12 \\
\hline
\end{tabular}

Presidencia de la República

\begin{tabular}{|c|c|c|}
\hline & $N .^{\circ} \operatorname{votos} 1 .^{a} \mathrm{v}$ & $N \cdot \stackrel{\circ}{ }$ votos $2 .{ }^{a} v$ \\
\hline Momir Bulatovic (SKCG). & 42 & 76 \\
\hline 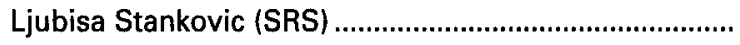 & 17 & 21 \\
\hline
\end{tabular}

En suma, el conjunto de los procesos electorales vividos en las distintas Repúblicas de Yugoslavia durante el año 1990 acabaría reafirmando la convicción de que resultaba imposible verificar un proceso democratizador homogéneo y equilibrado en el conjunto del territorio yugoslavo, toda vez que tanto los resultados electorales obtenidos como las actuaciones políticas anteriores y posteriores a esos comicios habían acabado demostrando la existencia de ideas muy diversas respecto de qué fuese una convivencia democrática. La decisión de croatas y eslovenos de perseverar en su proceso de democratización y de integración europea acabaría requiriendo del conjunto de pueblos de Yugoslavia un replanteamiento en profundidad de las bases de su convivencia, del que no tardaría en concluirse la inevitabilidad de la ruptura de la Federación. 


\section{FUENTES BIBLIOGRÁFICAS}

Los cuadros que acompañan el presente texto son de elaboración propia. Los datos numéricos en que se apoyan provienen, no obstante, de las siguientes fuentes:

\section{República Democrática Alemana}

Gıowskı, Wolfgang G.: "Demokratischer (Neu-) Beginn in der DDR", Zeitschrift für Parlamentsfragen, n.․․ 1/90, págs. 4 a 22, Opladen, 1990.

\section{Bulgaria}

AsHLEY, Stephen: "(Elections in Eastern Europe:) Bulgaria", Electoral Studies, n. 9 9/4, págs. 312 a 318, Oxford, 1990.

\section{Checoslovaquia}

Hospodárské Noviny, 14 de junio de 1990.

Lidové Noviny, 26 de octubre de 1990.

Pravda, 11 de junio de 1990.

Rudé Pravó, 26 de octubre de 1990.

WIGHTMAN, Gordon: «The Collapse of the Communist Rule in Czechoslovakia and the June 1990 Parliamentary Elections", Parliamentary Affairs, n. $44 / 1$, págs. 94 a 113, Oxford, 1991.

\section{Hungría}

HibBing, John R., y PAtTerson, Samuel C.: «A Democratic Legislature in the Making: The Historic Hungarian Elections of 1990", Magyar Politikatudomány Társaság Évkönyv, págs.128 a 149, Budapest, 1990.

KöRÖSÉNYI, András: "(Elections in Eastern Europe:) Hungary", Electoral Studies, n.ㅇ 9/4, págs. 337 a 345, Oxford, 1990.

RACZ, Barnabas: "Political Pluralisation in Hungary: the 1990 Elections", Soviet Studies, n. 43/1, págs.107 a 136, Glasgow, 1991.

SzoBoszlAl, György: "Az 1990 öszi önkormányzati választásokról». Manuscrito inédito, Budapest, 1991. 


\section{Polonia}

Astié, Pierre, y Breillat, Dominique: "Repères étrangers: Pologne", Pouvoirs, n.. 57 , págs.166 a 167, París, 1991.

PelczYNSKı, Zbigniew, y Kowalskı, Sergiusz: «(Elections in Eastern Europe:) Poland", Electoral Studies, n.ำ 9/4, págs. 346 a 354, Oxford, 1990.

\section{Rumanía}

Gabany, Anneli Ute: “Die Wahlen in Rumänien”, Südosteuropa, n.. 39/7-8, págs. 405 a 428, Múnich, 1991.

Campeanu, Pavel; Combes, Ariadna, y Berindel, Minhea: «România, înainte si dupa 20 mai», Humanitas, 147 págs., Bucarest, 1991.

\section{Las Repúblicas de la URSS}

SLIDER, Darrell: "(Elections in Eastern Europe:) The Soviet Union", Electoral Studies, n. 9/4, págs. 295 a 302, Oxford, 1990.

TAAGEPERA, Rein: "(Elections in Eastern Europe:) The Baltic States", Electoral Studies, n. 9/4, págs. 303 a 311, Oxford, 1990.

YAKEMUK, Romain: «Les Republiques Baltes et la crise du federalisme sovietique", Studia Diplomatica, n.ำ XLIII / 4, 5 y 6, págs. 192 y ss., Bruselas, 1990.

\section{Las Repúblicas de Yugoslavia}

Allcock, John B.: "Yugoslavia", en Szajkowski, Bogdan (ed.): New Political Parties of Eastern Europe and the Soviet Union, Longman, Harlow, 1992.

ANDREJEVICH, Milan: "The Election Scorecard for Serbia, Montenegro and Macedonia", RFE/RL Report on Eastern Europe, n. ${ }^{\circ}$ 11/1990, págs. 37 a 39, Múnich, 1990.

CoHen, Lenard J.: Broken Bonds. The Disintegration of Yugoslavia, Westview Press, Boulder/San Francisco, Oxford, 1993.

Grdesic, Ivan; KASAPovic, Mirjana; SIBER, Ivan, y ZaKoseK, Nenad: Hrvatska $u$ izborima "90», Naprijed, Zagreb, 1991. 